University of Missouri-Kansas City School of Law

UMKC School of Law Institutional Repository

\title{
Entertainment As Crime Prevention: Evidence from Chicago Sports Games.
}

Hannah S. Lacqueur

Ryan W. Copus

University of Missouri-Kansas City

Follow this and additional works at: https://irlaw.umkc.edu/faculty_works

Part of the Law Commons

\section{Recommended Citation}

Hannah S. Lacqueur \& Ryan W. Copus, Entertainment As Crime Prevention: Evidence from Chicago Sports Games., 20 Journal of Sports Economics 344 (2018).

Available at: https://irlaw.umkc.edu/faculty_works/214

This Article is brought to you for free and open access by the Faculty Scholarship at UMKC School of Law Institutional Repository. It has been accepted for inclusion in Faculty Works by an authorized administrator of UMKC School of Law Institutional Repository. 


\title{
Entertainment as Crime Prevention: Evidence from Chicago Sports Games
}

Hannah Laqueur \& Ryan Copus*

\begin{abstract}
The concern that mass media may be responsible for aggressive and criminal behavior is widespread. Comparatively little consideration has been given to its potential diversionary function. This paper contributes to the emerging body of literature on entertainment as a determinant of crime by analyzing Chicago by-the-minute crime reports during major sporting events. Sports provide an exogenous infusion of TV diversion that we leverage to test the effect of entertainment on crime. Because the scheduling of a sporting event should be random with respect to crime within a given month, day of the week, and time, we use month-time-day-ofweek fixed effects to estimate the effect of the sporting events on crime. We compare crime reports by the half hour when Chicago's NFL, NBA, or MLB teams are playing to crime reports at the same time, day, and month when the teams are not playing. We conduct the same analysis for the Super Bowl, NBA Finals, and MLB World Series. The Super Bowl generates the most dramatic declines: total crime reports decrease by approximately 25 percent (roughly 60 fewer crimes). The decline is partially offset by an increase in crime before the game, most notably in drug and prostitution reports, and an uptick in reports of violent crime immediately after the game. Crime during Chicago Bears Monday night football games is roughly 15 percent lower (30 fewer crimes) than during the same time on non-game nights. Our results show similar but smaller effects for NBA and MLB games. Except for the Super Bowl, we find little evidence for temporal crime displacement before or after the games. In general, we find substantial declines during games across crime types - property, violent, drug, and other - with the largest reductions for drug crime. We believe fewer potential offenders on the streets largely explain the declines in crime.
\end{abstract}

- PhD Candidates, University of California, Berkeley Law School, Jurisprudence and Social Policy. The authors shared equally in authorship and are listed alphabetically. We are extremely grateful for the guidance and comments from our advisors Kevin Quinn and Frankline Zimring. We also want to thank Catherine Albiston, Jeff Fagan, Rob 


\section{Introduction}

-"Do this research...If we don't have a season, watch how much evil, which we call crime, watch how much crime picks up if you take away our game...[People have] nothing else to do."

--Ray Lewis, Super Bowl MVP

This paper tests Ray Lewis's hypothesis. ${ }^{1}$ We analyze Chicago by-the-minute crime reports during major sporting events and find there are significant reductions in crime during televised games. The evidence suggests these reductions are the result of potential offenders being diverted from criminal activity watching the game on television. Importantly, at least in the short-term, the reductions appear to represent foregone criminal opportunities -- crime does not increase before or after most games.

The concern that mass media may be responsible for aggressive and criminal behavior is widespread, however, comparatively little consideration has been given to its potential diversionary function. Social science research on the entertainment-crime connection has been mostly experimental, focusing primarily on the possible behavioral effects of mass media; whether viewing violent films promotes violent tendencies, for example (Anderson and Bushman, 2001, 2002; Anderson, 2004; Uhlmann and Swanson, 2004; Adachi and Willoughby, 2011). Some scholars have made the conceptual point that entertainment may in fact play a crime-reducing role by keeping people off the streets (e.g., Zimring \& Hawkins, 1997), but there has been little empirical testing of the idea. In this paper, we find strong evidence that entertainment, specifically the entertainment provided by televised sports games, reduces crime

\footnotetext{
${ }^{1}$ Ray Lewis's claim that a National Football League (NFL) lockout would lead to higher crime was largely dismissed. Blogs and commentators mostly mocked him; social scientists concluded there was no data to support the claim (e.g. http://www.politifact.com/georgia/statements/2011/jun/17/ray-lewis/ray-lewis-crime-claim-getsflagged/) . Ray Lewis was not explicit as to why he thought cancelling NFL games would lead to increases in crime. He suggests crime would increase because people would have "nothing else to do" if the NFL season were cancelled due to the lockout. This theorization is compatible with our own: people watching NFL games are less likely to engage in crime. He also stated, however, "[t]here's too many people that live through us," which suggests general malaise due to the absence of NFL football could increase crime. Our paper does not address the latter theory. 
in the short-term by up to 25 percent.

We compare Chicago crime reports by the half hour when Chicago's National Football League (NFL), National Basketball Association (NBA), or Major League Baseball (MLB) teams are playing to crime reports at the same time, day, and month when the teams are not playing. We conduct the same analysis for the Super Bowl, NBA Finals, and MLB World Series. We estimate the effect of televised sporting events on crime in the city by exploiting the fact that the scheduling of sports games should be unrelated to crime within a given month, day of the week, and time-slot to. Consider, for example, the Chicago Bears' regular season schedule. During a given NFL season one or two Bears games are scheduled on a Monday night. By comparing crime reports on the Monday nights when they happen to play to crime reports on non-game Mondays (when they instead played on Sunday), we estimate the causal effect of Bears games on crime. ${ }^{2}$ Unlike most other analysis of the relationship between sports and crime, we target the link between television viewership rather than stadium attendance by focusing on a large city, where stadium attendance is minimal as compared to the number of television viewers.

Our results show overall crime in Chicago during Bears Monday Night Football games is approximately 15 percent lower than the same time on Monday nights when the Bears are not playing. The Super Bowl generates even more dramatic crime reductions. Crime is about 25 percent lower during Super Bowl game coverage, which amounts to roughly 60 fewer crimes. We find similar but smaller effects for the NBA and MLB. Importantly, we find little evidence of effects in the hours before or after games or the day following a game. ${ }^{3}$ The absence of temporal crime shifts is theoretically important, as it speaks to the question of displacement and the role of

\footnotetext{
${ }^{2}$ This is likely a conservative estimate. Because we are comparing Monday night Bears games to Monday nights within the same month in which there will be other football games airing, we estimate the effect of TV entertainment that a Bears game provides above and beyond that provided by other NFL games (See Section III C). ${ }^{3}$ As we discuss in greater detail in Section V (B), we test for short-term reductions in crime (the day of and day after a sporting event). Though we do not generally find evidence of displacement, we cannot speak to whether the sports games produce long-term aggregate reductions in crime.
} 
opportunity in determining criminal behavior. An opportunity denied to an individual, perhaps because he or she is watching sports (or playing video games), may be a crime prevented rather than shifted to another time or place. Methodologically, the fact that crime is significantly affected only during game hours provides assurance that it is indeed the game driving the results and not some unobserved feature of game days such as a blizzard or heat wave.

The consistent drop across all crime types (violent, property, drug and other) in conjunction with the absence of displacement before or after games, suggests fewer potential criminals on the streets, diverted from crime and towards television, best explains the crime reductions we find. ${ }^{4}$ As we discuss in Section V, other possibilities -- reduced criminal opportunities, reduced crime reporting, or reduced law enforcement - do a poor job of accounting for the consistent and widespread declines.

Our analysis has important implications for the study of crime and its control. First, the reductions in crime we find during sports games speaks to the nature of criminal behavior itself. Some share of crime may be best understood not as a predetermined and calculated activity but rather as itself recreation (Zimring \& Hawkins, ch 8, 1997). The reductions we find may be interpreted as the substitution of one diversionary activity with another. Relatedly, the absence of significant short-term temporal displacement supports a corollary theoretical point: criminal opportunities are important in determining not only how crime is distributed, but also its volume. There is not a set "demand" for criminal activity. Rather, some amount of crime is opportunistic and situational -- if prevented today, it does not inevitably occur tomorrow. The idiosyncrasies of the immediate situation or context are important determinants of crime. Traditional accounts of the etiology of crime have mostly looked either to "root" causes, whether biological,

\footnotetext{
${ }^{4}$ While we are able to break out crime reports into the broad categories of violent, property, drug, and other, we do not have enough data to explore effects on specific crimes such as domestic violence. 
psychological, macro-sociological and economic, or at variation in policy -- changes in police manpower or strategy, for example. On the other hand, "Routine Activities" theorists have drawn attention to the importance of everyday features of life that can have a significant impact on criminal activity (e.g. Felson and Clarke, 1993). Our results support these situational theories of crime.

Second, our findings suggest entertainment may actually serve a pro-social crime preventative function. Social scientists have paid little attention to this possibility. While there is a vast literature analyzing the psychological effects of viewing violent movies, and television, or playing video games, the social benefits of people having something fun to do have been largely dismissed or unexplored. ${ }^{5}$ Alternative leisure activities and entertainment can substitute for criminal activity, and the benefits may be substantial.

\section{Literature Review}

\section{A. Media Effects}

The psychological research on the behavioral effects of viewing violent media, whether video games, television or movies, has consistently found that subjects act more aggressively (e.g., Anderson and Bushman, 2001, 2002; Anderson, 2004; Uhlmann and Swanson, 2004; Adachi and Willoughby, 2011). More recently, however, a handful of papers have explored the hypothesis that any increase in aggressive tendencies caused by violent media may be countered by its diversionary effect. Dahl and DellaVigna (2009) find violent movie attendance reduces violent crime in the short-term by between 1 to 2 percent. This net decline includes a drop in

\footnotetext{
${ }^{5}$ The idea of recreation as crime prevention was central to the 1990s proposals for community activities like "midnight basketball." Conservatives, who said such programs could never reduce crime and amounted to "coddling criminals," readily dismissed the proposals. But while midnight basketball was mocked and unfunded, the effects we find for Monday Night Football suggest the core theory has merit.
} 
crime both during and in the hours immediately following movie attendance. They theorize the decline is a function of "voluntary incapacitation:" movie attendance offers a substitute for other alternative aggressive activities. The authors concede violent movies may have an "arousal" effect, evidenced by their finding that there are smaller reductions in violence after more violent movies relative to mildly violent movies. But the authors conclude any arousal effect is swamped by the time-use effect.

Cunningham, Engelstätter, and Ward (2011) investigate the effect of violent video games on violent crime. They use the release of highly rated games as an instrument for increased video game play, and conclude playing violent video games produces an overall decrease in violent crime. As Dahl and DellaVigna similarly concluded, Cunnignham et al suggest this net decline comprises both a positive behavioral effect -- violent video games encourage aggressive behavior -- and a larger negative voluntary incapacitation effect. Individuals substitute real-world aggressive conduct for video game play. Ward (2011) looks at the association of video game stores, movie theaters, and sports stores with crime rates, finding that additional sports and game stores are associated with decreases in crime.

\section{B. Sporting Events and Crime}

There is a small empirical literature examining sports and crime specifically. Several studies have focused on the effect of televised games, football in particular, on rates of domestic violence. These studies are concerned with the effects of the game's content rather than time-use trade-offs. Gantz, Bradley, and Wang (2006) engaged in the earliest of such studies collecting data from 15 local police departments, including Chicago, from 1996-2002 to examine rates of domestic violence during football games. The results suggest a small increase in domestic violence reports: Chicago, for example, would experience 3.5 more domestic violence incidents 
on the days in which the Bears were playing. Card and Dahl (2011) study the effect of unexpected NFL football game wins and losses on rates of family violence. They find that upset losses (defeats in which the home team was predicted by the Las Vegas odds-makers to win by four or more points) lead to a 10 percent increase in domestic violence. Neither expected losses nor unexpected wins (victories when the home team was predicted to lose) have a significant impact on domestic violence. Kirby, Francis, and O'Flaherty (2013) study domestic abuse reports to an English police force during soccer matchers. They find substantial increases on days in which the English national team played, with higher increases when the team lost.

A second set of sports and crime studies have looked at the at the effect of sports games on crime rates more generally, focusing in particular on the effect of mass gatherings at sport stadiums (as opposed to the effect of television viewership, the focus of our study). ${ }^{6}$ Marie (2010) analyzes soccer matches in London and finds no effect on violent crime but property crime increases for home games and decreases for away games. The increase in property crimes during home games is hypothesized to be the result of fan concentration and police displacement; decreases in property crime during away games is hypothesized to be due to voluntary incapacitation of potential offenders attending the matches. Rees and Schnepel (2009) test the effect of college football matches on crime. They find sharp increases in the host community's assaults, vandalism, arrests for disorderly conduct and alcohol-related offenses, with particularly sharp increases for upset losses. Finally, most recently, Kalist and Lee (2014) test for the effect of NFL games on daily crime rates in a handful of cities. Specifically, using two years of daily crime data and NFL schedules for Baltimore, Detroit, Miami, Newark, New Orleans, LA,

\footnotetext{
${ }^{6}$ A related but slightly different analysis done by Baumann et al (2012) attempts to estimate the effect of spectator sports on annual local crime rates. They find the presence of a sport franchise or major sporting event in a city has no effect on property or violent crime, with the exception of the Olympics and Super Bowl: cities that host the Olympics experience a 10 percent increase in property crime during the year of the games; the Super Bowl is associated with a 2.5 percent decrease in violent crime during the year.
} 
Philadelphia, St. Louis, and Washington, DC, the authors assess whether home games, by concentrating people at a sports stadium, increase crime. Kalist and Lee estimate NFL home games increase crime by $2.5 \%$, statistically significant at the $10 \%$ level.

The apparent discrepancy between these previous studies' findings of some crime increases and our finding of game-generated crime declines can be explained by differences in the scope and context of analysis. Our results do not preclude the possibility that domestic violence may increase during football games; we simply cannot assess individual crime type differences given the small time increments that are the unit of our analysis. With respect to the second set of studies on sports and crime more generally, the divergence is likely related to the ratio of television watching to stadium attendance. Chicago is both home to one of the smallest NFL stadiums in the nation and is at least four to five times more populated than most of the cities included in the city study done by Kalist and Lee. The more than 2.5 million people living in Chicago dwarf a stadium crowd of 62,000 at Soldier Field. On the other hand, one could easily imagine New Orleans, with a population under 400,000, experiencing relatively large crime effects from a stadium crowd of 75,000. Furthermore, the statistically and substantively strongest results from Kalist and Lee actually support our study: they find crime decreases by almost $10 \%$ on playoff game days, the days in which one would expect the ratio of television watching to stadium crowds to be at its highest.

\section{Displacement and Criminal Opportunity}

The more general literature on crime displacement is also relevant to our study of the effect of entertainment on crime. Insofar as there is a self-incapacitation function of televised 
sports game watching, or video game play, as Ward and Cunningham (2011) suggest, this would be of little societal benefit if individuals simply shifted all of their criminal activity to other times. And in fact, much of the empirical literature on displacement indicates that criminal behavior does not necessarily or completely shift in time, place, or kind (e.g., Weisburd, David, Laura A. Wyckoff, Justin Ready, John E. Eck, Joshua C. Hinkle, and Frank Gajewski, 2006). Jacob, Brians, Lefgren and Moretti (2007), for example, use the randomization inherent in weather and find substantial, but not complete, displacement. They suggest a 10 percent increase in violent crime due to a weather shock results in a 2.6 percent decrease the following week and 5.4 percent increase over the following month. For property crimes, the authors find a 10 percent increase results in a 2 percent decrease the following week. ${ }^{7}$ Braga, Papachristos, and Hureau's (2012) review of the experimental and quasi-experimental evaluations of "hot spots" policing suggests concentrating police resources in crime hot spots produced significant reductions in crime in the majority of studies and importantly did not lead to physical crime displacement in surrounding locations. In fact, research suggests that place-based interventions are more likely to produce a diffusion of benefits - i.e. decreases in crime in the surrounding areas rather than the displacement of crime (Weisburd \& Telep, 2010; Weisburd, David, Laura A. Wyckoff, Justin Ready, John E. Eck, Joshua C. Hinkle, and Frank Gajewski, 2006).

Researchers have studied the role of opportunity and activity in determining crime in a number of contexts and settings. Jacob and Lefren (2003) study the short-term effect of extra school days on juvenile crime. They find school supervision provides an incapacitating function -

\footnotetext{
${ }^{7}$ Ray Lewis's claim that crime would rise due to the 2011 NFL lockout also generated a small collection of analyses. Although it was never rigorously tested by academics, Politifact.com, an organization that fact-checks statements made in U.S. politics, took up the challenge of checking the Super Bowl MVP's statement (http://www.politifact.com/georgia/statements/2011/jun/17/ray-lewis/ray-lewis-crime-claim-gets-flagged/). The organization rated it false, but it relied on admittedly small sample sizes and non-scientific studies. Criminologist James A. Fox also weighed in. Leveraging the fact that there is/are no NFL games the week before the Super Bowl, he compared crime during the week before the Super Bowl and the week of the Super Bowl in 2006, 2007, and 2008 and found no differences in crime.
} 
- property crime decreases by 14 percent on days in which school is in session. But school also serves to increase juvenile interactions and thereby increases levels of violence. Overall, the authors find violent crime increases by 28 percent during days in which school is in session. ${ }^{8}$ More generally, the literature on the relationship between employment and crime (e.g. Brunette, 2002; Duwe, 2012) hypothesizes unemployment may increase crime not only because it might drive people to illegal sources of income, but also because employment keeps people occupied and away from criminal activity.

As we detail below, we do not find offsetting increases in crime in the hours or days immediately before or after a televised sports game. This provides support for the theory that a crime prevented may truly be a crime saved; crime is not simply displaced. Nonetheless, our study cannot speak to long-term displacement. We therefore cannot rule out the possibility that the criminally inclined, knowing that they will not engage in crime while watching an upcoming game, could choose to commit crime in the days or weeks before or after the game instead.

\section{Data and Analysis}

\section{A. Chicago Crime Reports.}

The crime data we use is provided by the city of Chicago Data Portal extracted from the Chicago Police Department's CLEAR (Citizen Law Enforcement Analysis and Reporting) system. ${ }^{9}$ The dataset contains crimes that are reported to the police and includes data for all days from January 2001 through December 2013. The data reflects all criminal incidents in which the police responded and completed a case report. The police may respond to a call but determine that a crime has not occurred, in which case a report will not be completed (CPD Research \&

\footnotetext{
${ }^{8}$ Notably, we do not find a similar phenomenon at work in our study. While televised sports games generate congregations of individuals in groups, because they likely share support for the same team, these group encounters appear not to engender overall increases in aggressive behavior.

${ }_{9}^{9}$ Available at: https://data.cityofchicago.org/Public-Safety/Crimes-2001-to-present/ijzp-q8t2; 10
} 
Development Division, personal communication, April 25, 2014). We aggregated the data into broad crime type categories: violent, property, drugs, and other using the classifications provided by the Chicago Police Department (CPD). "Other" includes all crimes categorized as "crimes against society" that are not narcotics offenses.

There are some clear recording errors in the dataset with respect to the precise date and time of an event. First, 12:00 a.m. and 12:00 p.m. of the first day of each month contains a disproportionate number of crime reports. The data is recorded on these dates as a matter of default when the time/day of the crime is unknown. We therefore exclude the first of every month from our analyses. Second, crime reports on the hour are systematically higher than other times. Again, these times are entered as a default when reporters cannot reasonably estimate the exact time of the crime. Because we aggregate crime by the nearest half hour and compare the same thirty-minute time blocks on sports game days relative to non-game days, this quirk does not ultimately affect our analysis

For the game dates, start times, and other game information for NFL, NBA, and MLB games, we collected schedules from sports-reference.com. For some sports games sportsreference.com did not provide start times. In these instances we supplemented the schedule data with cbssports.com. We analyze a total of 12 Super Bowl games, 186 Sunday Bears games, 18 Monday night Bears games (11 wins and 7 losses), 68 Bulls Playoff Games, 94 NBA Finals games, 34 Cubs and White Sox playoff games, and 70 World Series games.

\section{B. Research Design}

To estimate the effect of sports games on crime we aggregate crime reports by the half hour and compare half hour blocks before, after, and during a game to the same half-hour blocks

\footnotetext{
${ }^{10}$ The list of crimes and their general categories - crimes against property, crimes against person, and crimes against society are listed at: http://gis.chicagopolice.org/clearmap/crime_types.html).
} 
on the same day-of-week and in the same month. All analyses use this time-day-month fixed effects design and include year dummy variables. ${ }^{11}$ Year dummies should not be needed for a correct model specification, as we have no a priori reason to believe that the frequency of games has changed systematically over the period of study. Nonetheless, because crime has systematically decreased over the study period, we include a dummy variable for each year as a precaution and as a means of increasing the efficiency of our estimators. Finally, because holidays may affect both game scheduling and levels of crime, we exclude all major holidays from the analysis. The models we estimate are of the following form:

$$
\text { Crimes }=\beta_{0}+\beta_{1} \text { Status }+\beta_{2} \text { Month-Day-Hour }+\beta_{3} \text { Year }
$$

where Crimes is the number of crimes reported during a half hour time-block, status is a series of indicators for the temporal relationship between the half hour time-block and a sports game (i.e., there is no game, the time-block is 3 hours before a game, 2.5 hours before a game, and so on until 3 hours after a game), MonthDayHour is a set of indicator variables for each time-block, and year is a series of dummy variables for the year. ${ }^{12}$

The coefficients of interest are those on the dummy variables indicating the relationship between a half-hour block and the start/end of a game. We do not have data on the official end time of the games, but we estimate that most games other than the Super Bowl end approximately three hours after beginning. There is some measurement error that will affect the

\footnotetext{
${ }^{11}$ We have also run the analyses with year-month dummies. The results do not change in any significant way. ${ }^{12}$ Our chosen model specification offers estimates of how televised sports games affect crime. Some readers have expressed interest in a slightly different question -- how does a game affect crime during the hours of the game independently of how a game affects crime during the day of the game? The inclusion of a game-day indicator variable provides a way to capture this later question. We present in the appendix the results of this alternative model for the two sports games in which we find the largest affects, the Super Bowl and Monday NFL games. The results are quite similar to our chosen specification, which should alleviate concerns that our findings are being driven by something particular about a game day as opposed to the actual game.
} 
estimates near the beginning and ends of games. For example, we regard a game starting at 8:40 as having started at 8:30. In addition, some games last longer than three hours or go into overtime. Coefficients on the half-hour blocks post game will therefore represent, in part, the effect of overtime periods on crime.

We estimate our model using ordinary least squares regression. For each individual game status coefficient we report heteroskedasticity-robust standard errors. For estimates of the total effect of each sporting event, we cluster standard errors by date, as crime during each aggregated half-hour time block is not independent of crime during other time blocks on the same day. For example, a particularly cold-weather day could reduce crime in multiple half-hour blocks. ${ }^{13}$

Percent estimates are derived from Poisson regression models. This is the standard model used for count data with zeros in the outcome variable, which precludes using a log-linear model (Nichols, 2010). The coefficient on each game status dummy variable can be translated into an approximate percentage change by $\exp (\beta)-1$ (Wooldridge, 2012). We also estimated negative binomial models, which are used to address over-dispersion. The estimates are not significantly different than Poisson estimates, and we do not report them here.

\section{More on Treatment and Control}

Before presenting our results, it is important to clarify our research design and its implications for interpretation. We leverage the exogenous infusion of television diversion provided by sports games to test for the effect of entertainment on crime. Without such an exogenous infusion, a simple regression of television viewership on rates of crime would likely

\footnotetext{
${ }^{13}$ Because in the first specification, the coefficients on each half-hour indicator are each purely a function of the crime rate during that particular half-hour time block on days when a game is on and the crime rate during that particular half-hour block when no game is on, the estimation does not involve any information from the game day and therefore clustering standard errors by date has no effect. It should be noted, however, that is is theoretically possible that unobserved game-timed events such as a blizzard could drive the results.
} 
be subject to omitted variable bias -- many things, such as weather, likely affect both crime and TV viewing. As we have argued above, the scheduling of major sporting events within a given month, day, and time should, however, both affect TV viewership and be random with respect to crime.

If the cost of data were not an impediment, we could directly measure, through Nielsen ratings, the effect of sporting events on TV viewership, and then the effect of the spike in viewership on crime. ${ }^{14}$ We do not currently have access to this data and thus estimate instead the "reduced form." The magnitude of this "reduced" effect will depend on two major factors: (1) the popularity of the sporting event and (2) the popularity of TV programming during the comparison days. What determines the magnitude of the diversion -- and ultimately the effects we find -- depends on the additional viewership the game generates. This is driven in part by game popularity: more popular games offer a stronger treatment "dose." But the magnitude of the diversion is also driven by our comparison or "control" days. Monday night Bears games provide an estimate of the effect of Bears games relative to a Monday night NFL game in which the local team is not playing. In this sense, the estimate as a measure of the effect of sports game watching on crime rates is conservative -- it is an estimate of the effect of the additional viewership generated by the Bears as compared to any other NFL game. In the case of the Super Bowl, on the other hand, there are rarely other major television events in the month in which the Super Bowl falls, and thus we are able to compare Super Bowl Sunday to "normal" television programming on an average Sunday in February.

\footnotetext{
${ }^{14}$ Nielsen ratings are, however, an imperfect measure of TV viewership and particularly so with respect to sporting events. Ratings are based upon the number of televisions tuned to a given station. They do not account for multiple viewers watching a program on a single device. This is particularly problematic with respect to measuring televised sporting events given that many sports games are social events watched in groups.
} 


\section{Results}

Table 1 summarizes the estimated reduction in crime during an average game for each type of sporting event. For each sporting event we run the linear model described above and sum the "game on" coefficients assuming an average game length is three hours plus a half hour of pre-game coverage; we assume the Super Bowl is four hours. The results show substantial and statistically significant effects for most sporting events across all crime type category. The drop in drug crimes is steeper than the drops we find in property or violent crime. Direct comparisons across sports should be made with caution. Differences in the size of the effects not only represent differences in the magnitude of "treatment" but also in how we are able to define our “control.” We, for example, derive estimates for Monday night Bears games by comparing Monday nights in which the Bears are playing with Monday nights when other NFL games are on television. The effects are thus derived from the additional viewership generated by the fact that the local team is playing, compared to the viewership of non-local team games. On the other hand, Super Bowl Sunday is compared to other Sundays in February, when there are no other major sporting events on television. 
Table 1. Chicago Crimes Prevented By A Professional Sporting Event (2001-2013)

\begin{tabular}{|c|c|c|c|c|c|}
\hline & Total & Property & Violent & Drugs & Other \\
\hline Super Bowl & $-58(-26 \%) * * *$ & $-18(-17 \%) * * *$ & $-9(-14 \%) * * *$ & $-25(-63 \%) * * *$ & $-7(-28 \%)$ \\
\hline Super Bowl w/ Pre Game Coverage ${ }^{15}$ & $-68(-18 \%) * * *$ & $-19(-11 \%) * * *$ & $-10(-9 \%) * * *$ & $-34(-49 \%) * * *$ & $-7(-18 \%)$ \\
\hline Monday Bears Game & $-32(-13 \%) * * *$ & $-5(-3 \%)$ & $-8(-11 \%) * *$ & $-13(-29 \%) * * *$ & $-6(-27 \%) * * *$ \\
\hline Monday Bears Win & $-46(-17 \%) * * *$ & $-15(-12 \%) * * *$ & $-9(-10 \%) * *$ & $-14(-29 \%) * * *$ & $-7(-36 \%) * * *$ \\
\hline Monday Bears Loss & $-11(-6 \%)+$ & $10(7 \%) *$ & $-7(-11 \%)$ & $-11(-27 \%) * * *$ & $-3(-18 \%)^{*}$ \\
\hline Sunday Bears Game & $-6(-3 \%)^{*}$ & $-1(-1 \%)$ & $-1(-1 \%)$ & $-4(-17 \%) * * *$ & $-1(-5 \%)+$ \\
\hline NBA Finals Game & $-10(-3 \%) * *$ & $-5(-4 \%) * *$ & $-4(-4 \%)+$ & $0(3 \%)$ & $-2(-5 \%)+$ \\
\hline Bulls Playoff Game & $-8(-2 \%) * *$ & $-5(-4 \%) * * *$ & $-1(0 \%)$ & $-2(-4 \%)+$ & $-1(-3 \%)$ \\
\hline World Series Game & $-5(-2 \%)$ & $-1(-1 \%)$ & $-2(-4 \%)+$ & $-1(-1 \%)$ & $-1(-5 \%)$ \\
\hline Cubs or White Sox Playoff Game & $-19(-7 \%) * * *$ & $-5(-5 \%)+$ & $-3(-4 \%)$ & $-9(-20 \%) * *$ & $-2(-6 \%)^{*}$ \\
\hline
\end{tabular}

***Significant at the 0.1 percent level. ${ }^{*}$ Significant at the 1 percent level. *Significant at the 5 percent level; Significant at the 10 percent level.

The crime savings estimates represents results from a series of models for each game type. The total crime savings estimate is derived from the sum of the "game on" coefficients of a linear model. For all games except the Super Bowl, we estimate the average length of a game is three hours and includes a half hour of pre-game coverage; the Super Bowl is estimated to be four hours. The percent crime reduction estimates are derived from a Poisson regression model. Standard errors are clustered by date. The percent reductions in crime estimates are derived from Poisson regression.

The following sections present the results for each sporting event in more detail.

\section{A. Crime During the Super Bowl}

The Super Bowl is always held on a Sunday afternoon, and coverage typically lasts from 1:30 pm, at which point pre-game commentary commences, through 5:30 pm, at which point the game kicks off, until 9:30pm, at which point the game concludes. Figure 1 plots average total crime reports by the hour on Saturday night through Monday morning. The red line represents average crime reports during non-Super Bowl weekends. The blue line represents the estimates of crime on Super Bowl weekends. Average crime on Super Bowl Sunday is slightly higher before pre-game coverage begins (four hours before the official start-time). This increase is driven primarily by above-average drug and prostitution reports. Crime reports begin to decline during pre-game coverage and are significantly lower until the end of the game, when they

\footnotetext{
${ }^{15}$ When changes in crime over the full course of the day are taken into account (7 a.m. - 11:30 p.m.), we find the following estimates for Super Bowl Sunday as compared to the average non- Super Bowl Sunday. Total crime: -43 (-6\%); property crime: -18 (-6\%); violent crime: -1 (-1\%); drug crime: $-31(-29 \%)$; other crime: 7 (8\%). 
converge to the mean.

\section{Figure 1}

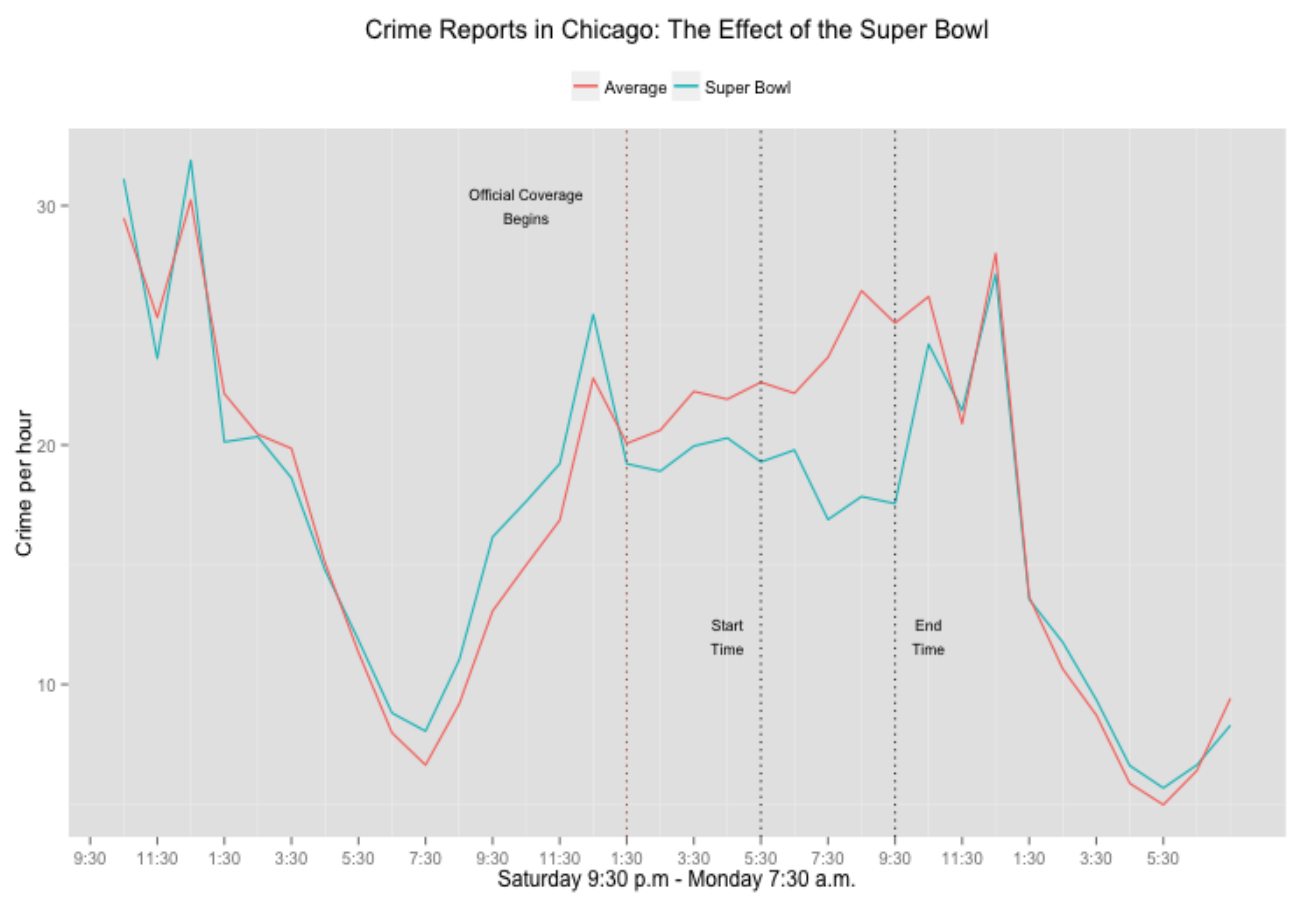

The Super Bowl regression results are presented in Table 2. The point estimate on each indicator variable represents the estimated difference in crime reports between each half-hour period on Super Bowl Sunday and the same half-hour periods on comparable non-Super Bowl Sundays. In total, there are close to 60 fewer crimes during the Super Bowl, which represents a reduction of approximately 25 percent. The largest drops during the Super Bowl for drug crimes: there are over 60 percent fewer drug offenses reported during the Super Bowl. Violent and property crime are down 15 to 20 percent during the game hours. We do, however, find a spike in violent crime after the game that cancels out any reductions found during the Super Bowl.

Figure 2 offers another illustration of the Super Bowl crime trends broken out by crime category. Here we present cumulative changes in crime over the course of the Super Bowl weekend, the same hours shown in Figure 1. That is, each trend represents the sum of the coefficients on the OLS model's time indicator variables beginning at $t_{\mathrm{o}}(9: 30 \mathrm{p} . \mathrm{m}$. Saturday 
night) through $t_{N}(7: 30$ a.m. Monday morning). So, for example, the figure reveals total crime coefficients are near zero Saturday night, meaning the eve before the Super Bowl looks no different than the average Saturday night. The total crime coefficients are positive and cumulatively rising Sunday morning before the game and then drop precipitously during the game, ultimately resulting in an additive effect well below the dashed zero line.

Table 2. Super Bowl Sunday: Crimes per Half-hour (OLS)

\begin{tabular}{|c|c|c|c|c|c|}
\hline & Total & Property & Violent & Drugs & Other \\
\hline $3.0 \mathrm{hrs}$ pre & $-3.381^{* * *}(0.949)$ & $-0.680(0.486)$ & $-0.852(0.582)$ & $-1.345^{*}(0.542)$ & $-0.364(0.433)$ \\
\hline $2.5 \mathrm{hrs}$ pre & $-2.417(1.745)$ & $-0.418(0.998)$ & $-0.314(0.660)$ & $-1.854^{* * *}(0.484)$ & $-0.437(0.559)$ \\
\hline $2.0 \mathrm{hrs}$ pre & $-0.385(1.250)$ & $-0.267(0.892)$ & $1.019(0.601)$ & $-0.966(0.602)$ & $-0.096(0.358)$ \\
\hline $1.5 \mathrm{hrs}$ pre & $-3.719(2.548)$ & $-1.649(1.161)$ & $0.258(1.319)$ & $-1.743^{* *}(0.534)$ & $-0.313(0.459)$ \\
\hline $1.0 \mathrm{hrs}$ pre & $-1.809^{*}(0.842)$ & $-0.321(1.045)$ & $-0.184(0.508)$ & $-1.101^{* *}(0.385)$ & $-0.115(0.326)$ \\
\hline $0.5 \mathrm{hrs}$ pre & $-5.409^{* *}(1.929)$ & $-2.328(1.357)$ & $-1.050(0.947)$ & $-1.119^{* *}(0.418)$ & $-1.173^{* *}(0.425)$ \\
\hline Game 0-.5 hr & $-2.037(1.489)$ & $0.470(1.048)$ & $-1.573^{* *}(0.566)$ & $-0.729(0.681)$ & $-0.231(0.539)$ \\
\hline Game .5-1 hr & $-4.349(2.332)$ & $-2.912^{*}(1.183)$ & $-1.201(1.004)$ & $-0.897^{*}(0.434)$ & $0.568(0.826)$ \\
\hline Game 1-1.5 hr & $-5.616^{* * *}(1.423)$ & $-2.121^{* * *}(0.623)$ & $-1.539^{*}(0.701)$ & $-1.656^{* * *}(0.377)$ & $-0.181(0.507)$ \\
\hline Game 1.5-2 hr & $-7.665^{* * *}(1.406)$ & $-2.146^{*}(0.991)$ & $-0.599(0.928)$ & $-3.949^{* * *}(0.508)$ & $-1.046^{*}(0.520)$ \\
\hline Game 2-2.5 hr & $-6.813^{* * *}(1.204)$ & -1.239 (0.827) & $-0.393(0.696)$ & $-3.909^{* * *}(0.406)$ & $-0.729(0.482)$ \\
\hline Game $2.5-3 \mathrm{hr}$ & $-11.369^{* * *}(1.917)$ & $-4.464^{* * * *}(1.176)$ & $-0.087(1.079)$ & $-4.1333^{* * *}(0.496)$ & $-2.461^{* * * *}(0.379)$ \\
\hline Game 3-3.5 hr & $-6.757^{* * *}(1.496)$ & 0.621 (1.462) & $-2.224^{* *}(0.765)$ & $-4.167^{* * *}(0.395)$ & $-0.923^{* *}(0.314)$ \\
\hline Game 3.5-4 hr & $-8.272^{* * * *}(1.850)$ & $-3.384^{* *}(1.280)$ & $-0.226(1.137)$ & $-4.222^{* * *}(0.502)$ & $-0.433(0.538)$ \\
\hline $0.5 \mathrm{hrs}$ post & $-1.823(1.616)$ & $0.290(1.260)$ & $1.300(0.694)$ & $-2.744^{* * *}(0.509)$ & $-0.630(0.418)$ \\
\hline $1.0 \mathrm{hrs}$ post & $-3.186(2.086)$ & $-2.558^{*}(1.028)$ & $2.404^{*}(1.080)$ & $-2.614^{* * *}(0.505)$ & $-0.316(0.742)$ \\
\hline $1.5 \mathrm{hrs}$ post & $0.338(1.675)$ & $1.123(0.745)$ & $0.353(1.168)$ & $-1.731^{* *}(0.548)$ & $0.572(0.403)$ \\
\hline $2.0 \mathrm{hrs}$ post & $-0.510(1.312)$ & $-1.817^{*}(0.719)$ & $2.638^{*}(1.179)$ & $-1.042(0.670)$ & $-0.029(0.382)$ \\
\hline
\end{tabular}

Notes: $* * *$ Significant at the 0.1 percent level. ${ }^{* *}$ Significant at the 1 percent level. ${ }^{*}$ Significant at the 5 percent level. 


\section{Figure 2}

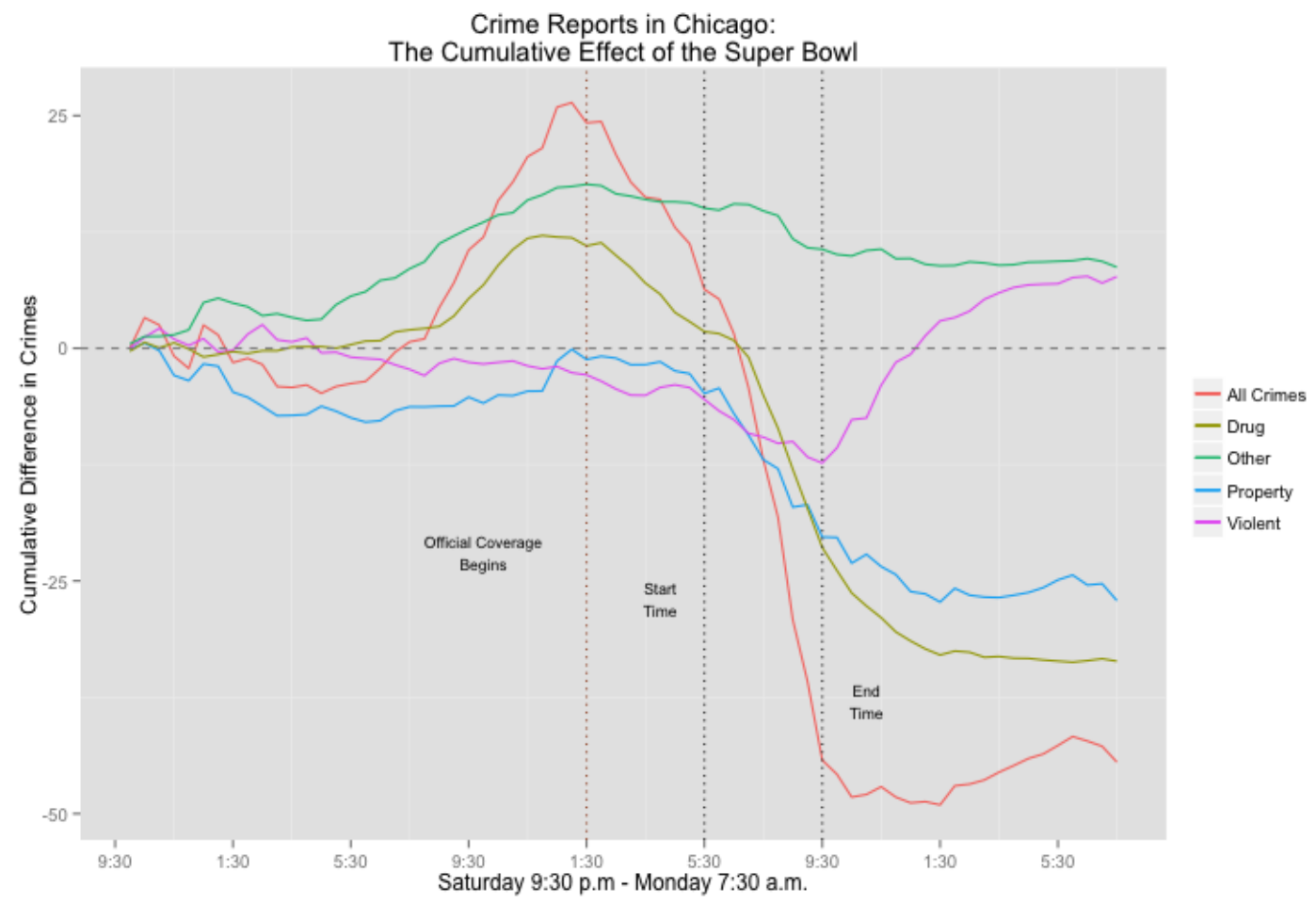

\section{B. Local Chicago Team Games}

For each of Chicago's major professional sports team - the Bears (NFL), the White Sox (MLB), the Cubs (MLB), and the Bulls (NBA) -- in addition to looking at the general effect on crime of a game, we also test for differential effects between home and away games and between home team wins and losses. As noted in the literature review, previous scholarship suggests there may be important differences across each of these categories. Rees and Schnepel (2009) show that college football games may generate increases in crime for the hosting location. Card and Dahl (2011), as well as Rees and Schnepel (2009), find games resulting in an unexpected win or loss may increase frustration levels which leads to rises in crime.

Because we expect results in a large city to be driven by television viewership rather than stadium attendance, we should not expect meaningful differences between home games and away games. Indeed, for none of the sports do we find crime effects are dependent on the 
location of the game. Insofar as home games may produce crime by concentrating individuals in and around stadiums, the million plus people watching the games on television swamp whatever stadium effect there may be. The relative importance of television viewership may explain the difference between our findings and those of Rees and Schnepel (2009), who report increases in crime during college games for hosting cities, and the findings of Kalist and Lee (2014), who report increases during home NFL games. As noted in the literature review, professional sporting events in Chicago generate a substantial number of television viewers as compared to college games and NFL games in the comparatively small cities studied by Kalist and Lee.

In general, we do not find differences in the magnitude of the effects for wins as compared to losses. The only exception is Monday Night Chicago Bears games: the game-time reductions in crime are driven almost entirely by winning games. We therefore present results for winning games and losing games separately. In part, the substantial reductions in crime during games the Bears won, but not for games that they lost, may be a matter of noise: the Bears were fairly successful on Monday nights in the last decade, so our sample size of games in which the Bears lost is only seven. The difference between winning and loosing games may also be due in part to the fact that a good team will draw more viewers and is also more likely to win.

\section{Chicago Bears Games}

Figure 3 illustrates the model predictions for Monday night Bears games resulting in a win compared to average crime reports trends over the course of a Monday in which the Bears are not playing. There are close to 50 fewer crimes on average during these Monday night Bears games as compared to nights without a Bears game; approximately 15 fewer property crimes on

these same nights, roughly 10 fewer violent crimes, and 15 fewer drug crimes. Figure 4 plots the cumulative difference between Monday nights with a Bears win and Monday nights without a 
Bears game. Table 3 shows our OLS regression estimates for the NFL Bears games in which the outcome was a win; table 4 presents the estimates for NFL Bear games in which the Bears lost. We also run the analysis for Bears games on Sundays relative to Sundays without Bears games. The aggregate reductions are presented in Table 1.

\section{Figure 3}

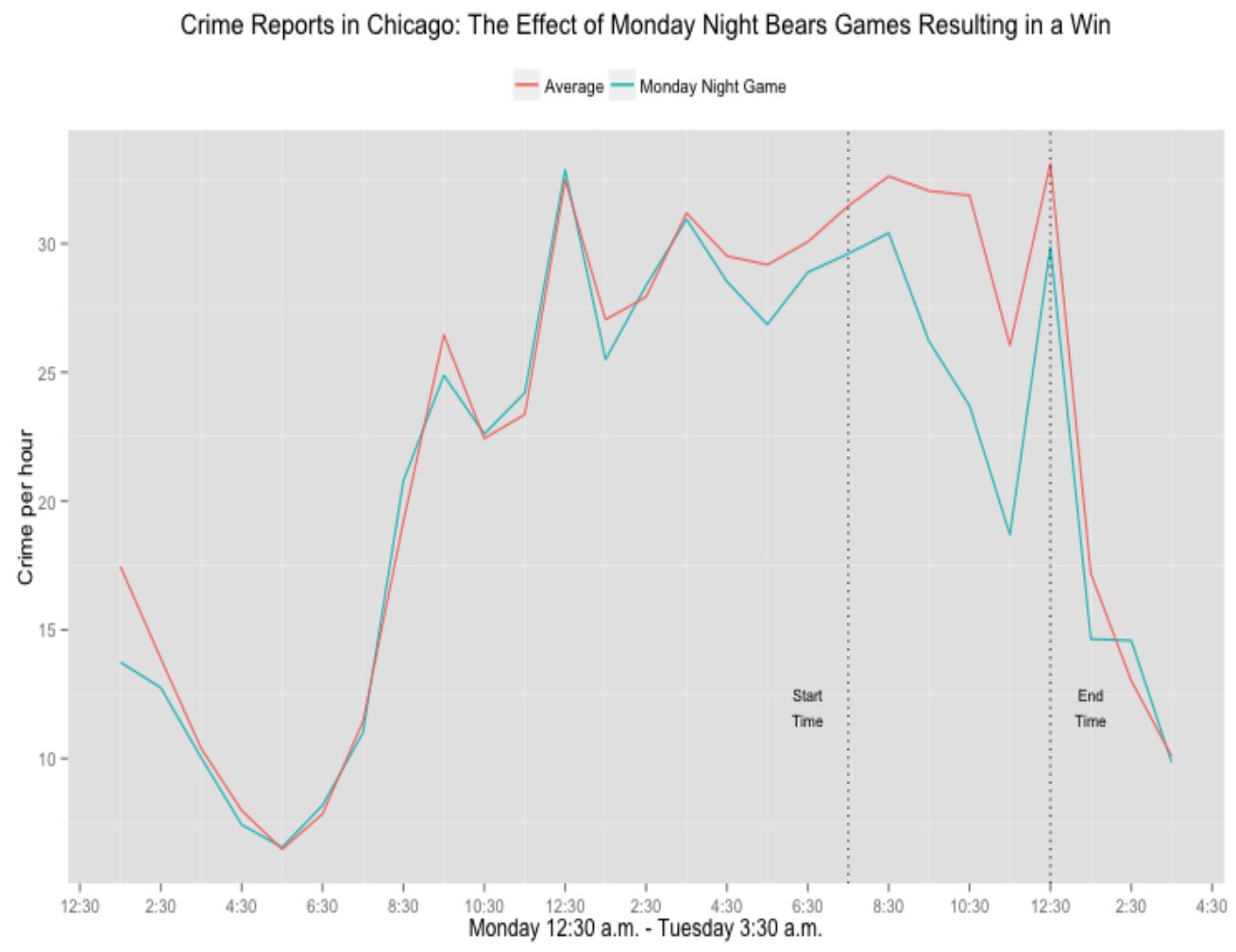


Figure 4

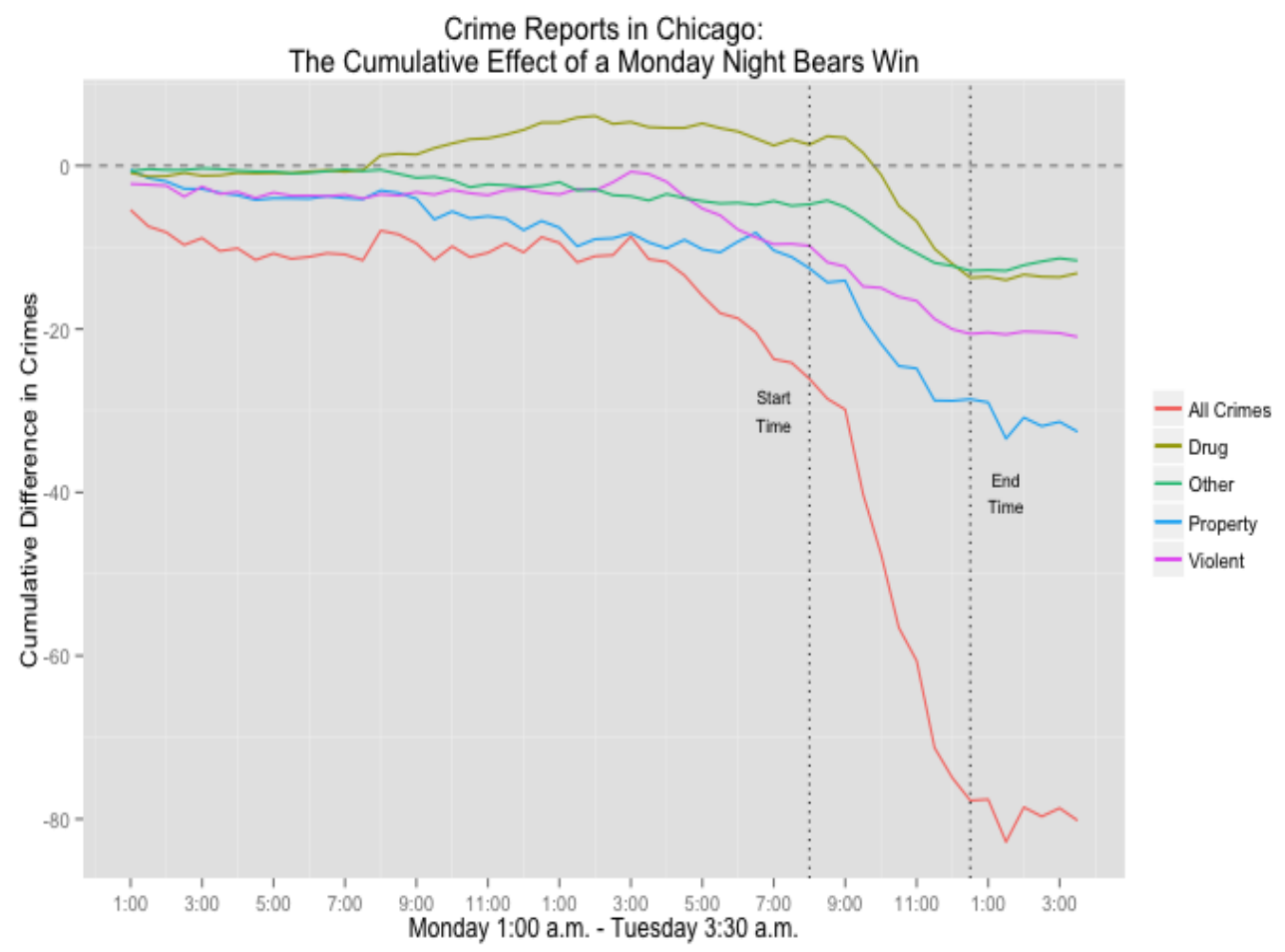

Table 3. Monday Night Bears Wins: Crimes per Half-hour

\begin{tabular}{|c|c|c|c|c|c|}
\hline & Total & Property & Violent & Drugs & Other \\
\hline $3.0 \mathrm{hrs}$ pre & $-0.245(0.853)$ & $1.450(0.965)$ & $-1.637(0.853)$ & $-0.308(0.395)$ & $0.109(0.337)$ \\
\hline $2.5 \mathrm{hrs}$ pre & $-1.333(2.524)$ & $1.218(2.255)$ & $-0.831(0.982)$ & $-0.752(0.498)$ & $-0.219(0.549)$ \\
\hline $2.0 \mathrm{hrs}$ pre & $-2.877^{* * * *}(0.827)$ & $-2.034^{*}(0.867)$ & $-0.718(0.613)$ & $-0.743^{* *}(0.287)$ & $0.504(0.370)$ \\
\hline $1.5 \mathrm{hrs}$ pre & $-0.045(2.114)$ & $-0.673(1.657)$ & $0.168(0.922)$ & $0.837(0.672)$ & $-0.550(0.363)$ \\
\hline $1.0 \mathrm{hrs}$ pre & $-1.586(0.944)$ & $-1.261(0.652)$ & $-0.123(0.983)$ & $-0.520(0.555)$ & $0.206(0.635)$ \\
\hline 0.5 hrs pre & $-2.037(2.863)$ & $-1.584(2.031)$ & $-1.881^{*}(0.812)$ & $1.144(0.936)$ & $0.501(0.752)$ \\
\hline Game 0-.5 hr & $-0.932(1.350)$ & 0.344 (0.591) & $-0.405(0.739)$ & $-0.083(0.590)$ & $-0.785^{*}(0.345)$ \\
\hline Game .5-1 hr & $-9.977^{* * *}(2.051)$ & $-4.483^{* *}(1.556)$ & $-2.314^{* * *}(0.495)$ & $-1.725^{*}(0.856)$ & $-1.336^{*}(0.666)$ \\
\hline Game 1-1.5 hr & $-6.887^{* * * *}(1.568)$ & $-2.958^{* * *}(1.095)$ & $-0.055(0.610)$ & $-2.569^{* * * *}(0.435)$ & $-1.588^{* * * *}(0.349)$ \\
\hline Game 1.5-2 hr & $-8.665^{* * * *}(1.803)$ & $-2.615^{*}(1.226)$ & $-0.975(0.810)$ & $-3.722^{* * * *}(0.451)$ & $-1.443^{* * *}(0.432)$ \\
\hline Game 2-2.5 hr & $-3.667^{* * * *}(0.760)$ & $-0.163(0.602)$ & $-0.374(0.774)$ & $-1.774^{* *}(0.594)$ & $-1.139^{* * * *}(0.231)$ \\
\hline Game $2.5-3 \mathrm{hr}$ & $-10.254^{* * *}(1.915)$ & $-3.791^{*}(1.512)$ & $-2.097^{*}(0.947)$ & $-3.250^{* * *}(0.420)$ & $-1.150^{* * *}(0.283)$ \\
\hline 0.5 hrs post & $-3.307^{*}(1.488)$ & $0.093(0.788)$ & $-1.138(0.669)$ & $-1.749^{* *}(0.569)$ & $-0.355(0.316)$ \\
\hline $1.0 \mathrm{hrs}$ post & $-2.372(2.676)$ & $0.334(1.367)$ & $-0.444(1.011)$ & $-1.591^{*}(0.685)$ & $-0.552(0.603)$ \\
\hline $1.5 \mathrm{hrs}$ post & $0.530(2.051)$ & $-0.257(0.636)$ & $0.281(0.988)$ & $0.230(0.758)$ & $0.111(0.434)$ \\
\hline $2.0 \mathrm{hrs}$ post & $-1.991(3.563)$ & $-3.174(3.432)$ & $0.183(1.204)$ & $-0.186(0.781)$ & $0.250(0.625)$ \\
\hline $2.5 \mathrm{hrs}$ post & $2.239(1.185)$ & $1.890^{*}(0.763)$ & $0.987(0.532)$ & $-0.015(0.576)$ & $-0.688^{* * *}(0.154)$ \\
\hline $3.0 \mathrm{hrs}$ post & $-1.638(1.333)$ & $-0.767(0.766)$ & $-0.471(0.890)$ & $-0.728^{*}(0.316)$ & $0.462(0.619)$ \\
\hline
\end{tabular}

Notes: $* * *$ Significant at the 0.1 percent level. ${ }^{* *}$ Significant at the 1 percent level. ${ }^{*}$ Significant at the 5 percent level.

Table 4. Monday Night Bears Losses: Crimes per Half-hour 


\begin{tabular}{|c|c|c|c|c|c|}
\hline & Total & Property & Violent & Drugs & Other \\
\hline $3.0 \mathrm{hrs}$ pre & $3.343(2.014)$ & $1.373(0.833)$ & $1.355(1.941)$ & $1.222^{*}(0.624)$ & $-0.469(0.526)$ \\
\hline $2.5 \mathrm{hrs}$ pre & $-0.171(1.095)$ & $-0.382(1.607)$ & $-0.456(1.110)$ & $0.057(0.749)$ & $-0.089(0.535)$ \\
\hline $2.0 \mathrm{hrs}$ pre & $2.127(2.472)$ & $0.013(1.713)$ & $-0.120(0.525)$ & $1.071^{*}(0.515)$ & $1.662(1.002)$ \\
\hline $1.5 \mathrm{hrs}$ pre & $0.110(3.701)$ & -0.755 (1.909) & $-1.378(1.395)$ & $1.494(0.933)$ & $0.675(0.441)$ \\
\hline $1.0 \mathrm{hrs}$ pre & $-0.311(2.734)$ & $-1.796(2.289)$ & $-1.555(1.371)$ & $2.420^{*}(1.141)$ & $0.864(0.831)$ \\
\hline 0.5 hrs pre & $-3.164^{* * * *}(0.627)$ & $-1.737(1.043)$ & $-2.067^{* *}(0.705)$ & $0.513(0.793)$ & $0.081(0.622)$ \\
\hline Game 0-.5 hr & $0.221(1.534)$ & $2.784^{*}(1.092)$ & $-1.224(1.131)$ & $-0.784(1.150)$ & $-0.376(0.249)$ \\
\hline Game .5-1 hr & $-2.293(1.660)$ & $0.963(0.912)$ & $-0.293(1.185)$ & $-1.763^{*}(0.895)$ & $-0.922(0.490)$ \\
\hline Game 1-1.5 hr & $2.277(2.420)$ & $5.849^{* *}(2.130)$ & $-1.376^{*}(0.578)$ & $-1.631^{*}(0.635)$ & $-0.872(0.489)$ \\
\hline Game $1.5-2 \mathrm{hr}$ & $-3.416(2.137)$ & $-0.158(1.181)$ & $-0.415(1.071)$ & $-2.621^{* * *}(0.592)$ & $-0.356(0.318)$ \\
\hline Game $2-2.5 \mathrm{hr}$ & $-2.090(2.177)$ & 0.149 (1.602) & $-1.219(1.621)$ & $-1.562(0.799)$ & $0.901(0.804)$ \\
\hline Game $2.5-3 \mathrm{hr}$ & $1.252(0.958)$ & $1.334(1.118)$ & $1.236(1.099)$ & $-0.723(0.818)$ & $-0.810(0.458)$ \\
\hline 0.5 hrs post & $-4.175^{* *}(1.520)$ & $0.445(1.031)$ & $-1.549(1.154)$ & $-2.125^{* * *}(0.464)$ & $-0.957(0.578)$ \\
\hline $1.0 \mathrm{hrs}$ post & $-3.614^{*}(1.518)$ & $-1.638(1.746)$ & $-0.647(0.721)$ & $-1.051^{*}(0.521)$ & $-0.230(0.467)$ \\
\hline $1.5 \mathrm{hrs}$ post & $2.378(1.971)$ & $3.856(2.218)$ & $0.005(0.614)$ & $-0.887(0.473)$ & $-0.101(0.516)$ \\
\hline $2.0 \mathrm{hrs}$ post & $-1.727(2.260)$ & $-0.129(1.987)$ & $0.134(0.717)$ & $0.228(0.543)$ & $-1.127^{* * * *}(0.281)$ \\
\hline $2.5 \mathrm{hrs}$ post & $-1.775(2.269)$ & $-2.059(1.566)$ & $0.234(1.130)$ & $0.273(0.528)$ & $-0.029(0.574)$ \\
\hline $3.0 \mathrm{hrs}$ post & $-1.430(1.597)$ & $-0.329(0.958)$ & $-0.381(0.780)$ & $0.272(0.366)$ & $-0.820^{*}(0.320)$ \\
\hline
\end{tabular}

\section{Chicago Bulls, White Sox, and Cubs}

The regression results for our analyses of the Chicago Bulls, White Sox and Cubs playoff games are reported in the appendix. Overall, we find small but consistently negative coefficients on drug and property crime for each half-hour period during Bulls games; violent crime patterns are less consistent. Chicago Cubs and White Sox playoff games also generate estimates that are consistent with but smaller than the estimates generated by the NFL games. Property, drug, and violent crimes are consistently lower during game half-hours. We estimate that Cubs or White Sox playoff games prevent 20 total crimes, roughly half of which are drug offenses.

\section{NBA and MLB Championship Games}

Crime is consistently lower during NBA finals games. These reductions include both lower violent and property crime reports, but, unlike the patterns we observe in the NFL 
analyses, the games have no effect on drug crimes. We do not find an effect from World Series games. As we discuss in greater detail in the following section, these results may be an artifact of our ability to compare World Series game days to comparable non-game days. World Series games are mostly in October, as are other baseball playoff games (including Cubs or White Sox games). We are thus comparing one "treatment dosage" to another, and this may explain why we do not find reductions in crime during World Series games. The regression output for the NBA championships and World Series are included in the appendix.

\section{Placebo Tests}

The fact that there are not NFL games on Tuesdays allows us to run a placebo test. We shift the game schedules for Monday night football games as though they were scheduled on a Tuesday before running our same fixed-effects regression model. We find no persistent trends for these fake game half-hour times, which provides reassurance that the results we find in our actual regression are not spurious. The full results are available in the appendix.

\section{Discussion}

\section{A. Summary}

The results presented above demonstrate clear reductions in violent, property, and drug crime reports in Chicago during the hours in which important sporting events are on television. Moreover, as we discuss in greater detail below, the hours before and after a game do not generally result in offsetting increases in crime. Thus, at least in the short term, major televised sports games produce real declines in crime reports.

The differences in the magnitude of the effects we find can be partially understood in relation to the "treatment," that is, the television entertainment provided by a game. A more popular game, such as the Super Bowl, offers a stronger "dose." The sizes of the effects we find 
generally correspond with game popularity. The Super Bowl, by far the most watched TV event, generates the largest crime reductions. TV ratings in Chicago indicate that local team NFL games, while less popular than the Super Bowl, are still significantly more popular than either the NBA or the MLB. But in addition to differences in treatment dosage, the days to which we compare each sporting event (our "controls") also differ in terms of their treatment dosage. In other words, some sporting events are compared to days in which other sporting events are on television.

The fact that some of our control days are "partially treated" by the television airing of non-local team games likely also explains some of the differences in the magnitude of effects we find. Sunday football games are, for example, consistently among the most watched television programs; fans frequently dedicate their Sundays to watching NFL games, whether or not their home team is playing. As such, Sunday Bears games may draw in only a small extra number of Chicago viewers. Similarly, our estimates of the effect of NBA and MLB playoffs rely on the additional viewership generated by local team playoff games relative to playoff games in which the local team is not playing. Likewise, Monday night Bears games are compared to Monday nights airing non-local NFL team games. Because some share of local team sports fans also watch the season games in which their team is not playing, our estimates likely understate the effect of sports entertainment on crime.

\section{B. The Mechanism \& Displacement}

Overall, we find little evidence of temporal crime displacement. The coefficients on the pre and post game indicators are mostly non-significant in all of our models. There are a few exceptions to the general pattern of no pre or post game effects. In particular, drug and prostitution offenses increase before the Super Bowl game and violence increases after the Super 
Bowl. The spike in violence following the Super Bowl is likely the result of the gathering and drinking during the game that manifests in aggression after the game when its incapacitative effects are over.

We also test for displacement by looking at crime the day after major sporting events. To maximize the likelihood of detecting crime displacement, we focus on the day after the Super Bowl and Monday night NFL wins, the two game types that generate the largest game-day reductions in crime. We first estimate the total game-day crime savings generated by these sporting events. On average, game days have 87 fewer crimes with a 95\% confidence interval of -142 to -31 . The day after these games, we estimate there are 37 fewer crimes with a $95 \%$ confidence interval of -82 to 8.8 . Thus, making the conservative assumption that the games only save 31 crimes, and the day after games results in 8.8 more crimes, only $28 \%$ of the crime savings are displaced to the following day.

We think the reductions in crime during sports games are best explained by games diverting potential offenders away from crime and towards television. There are, however, other potential explanations. One alternative account would suggest crime is lower during sporting events, not because potential offenders are inside watching the game, but rather because sports games generate conditions that offer fewer criminal opportunities. Both potential victims of crime and potential witnesses to crime may be kept inside and off the streets when games are on television. While fewer potential victims on the streets could help explain reductions in violent crime during games, it does not explain the drop in property crime. If anything, we might expect property crime to increase with fewer non-offenders on the streets -- abandoned streets present a perfect opportunity for looting. On the other hand, if the streets are abandoned, this might mean everyone is at home watching the game and potential offenders would be afforded fewer 
opportunities to commit home-based property offenses. This could help explain the decrease in property crime. But because major sporting events are often watched in groups, there may actually be more unguarded homes during a game night. We therefore think it unlikely that the decline in crime is due to fewer opportunities for potential offenders.

Another possibility is that crime reporting, not crime, is lower during sports games. People who would usually report a crime might be distracted by the game and therefore be unaware or unmotivated to make the report. This seems implausible for most violent crimes. It is plausible for property crime, but if this were the case we would expect reports to spike in the hours after the game as people returned to their homes or cars and discovered evidence of theft or vandalism. We find no evidence of such spikes in reporting.

Finally, it is possible that crime reports are lower because law enforcement officials, rather than making arrests, are busy watching or listening to the game. This is an unlikely explanation for the consistent declines we find in all crime categories during sports games. We would expect most property and violent crimes to be reported by the citizenry and not generally subject to police discretion. On the other hand, police discretion may well explain the particularly large reductions in drug crimes that we find during sports games. The discretionary nature of drug law policing is well known (Skogan \& Frydl, 2004). Drug crimes, like all "victimless" crimes, are rarely reported to police and are therefore, in significant part, the product of enforcement priorities and proactive targeting rather than a reflection of changes in drug supply or use (e.g. Warner \& Coomer, 2003). While it is likely the declines in drug offenses during games are, at least in good part, explained by fewer individuals on the streets engaging in drug activity, the drug effects above and beyond what we see for other crimes may well be explained by the failure of police to pursue drug activity because they are themselves distracted 
by the game. In summary, we think the most plausible explanation for the effects we find is that potential offenders are diverted from crime by the televised airing of sports games.

\section{Conclusion}

The fact that we find significant reductions in crime during televised sports games implies some individuals trade off participating in criminal activity for watching sports. This lends support to theories of crime that suggest some share of criminal behavior is recreational and opportunistic. If crime is not predetermined and calculated but rather is itself a form of recreation, the drops we find are not surprising -- they represent the substitution of one diversionary activity for another. The absence of significant short-term temporal displacement underscores the importance of the immediate situation or context as determinants of crime. While we don't know about idle hands, our paper suggests that idle eyes are the devil's playground.

Our findings speak not only to theories of criminal behavior but also have important practical implications. First, our results are relevant to the debate over the effects of entertainment on crime. While it has been suggested that the proliferation of modern technologies such as TV, video games, and online social networking may play a crime-reducing role by diverting individuals who might otherwise be at risk of engaging in criminal activity (Griffiths \& Sutton, 2013), the idea has been subjected to relatively little empirical testing. We find strong evidence that entertainment, specifically the entertainment provided by televised sports games, can reduce criminal activity. The debate surrounding the effect of media on criminal behavior has been too narrowly focused on the psychological link between violent entertainment and aggression. Whatever short-term aggression-inducing effects movies, television, or video games have may be negligible in comparison to their diversionary power. 
Our findings are also relevant to more immediate and narrow issues. For example, our results have implications for the current debate over whether to expand the NFL season or increase the number of weeknight games. If other weeknight games generate crime reductions similar to Monday night games and long-term crime displacement isn’t complete, additional game nights may have social benefits. Finally, most major sports seasons are played during lowcrime winter months rather than in the summer when crime is substantially higher (roughly 30 percent higher in Chicago). Sporting events aired in the summer -- traditionally a time of reruns and second-rate television -- could generate real crime savings. 


\section{References}

Adachi, Paul JC, and Teena Willoughby. "The Effect of Video Game Competition and Violence on Aggressive Behavior: Which Characteristic has the Greatest Influence?." Psychology of Violence 1.4 (2011): 259.

Anderson, Craig A, and Brad J Bushman. "Effects of Violent Video Games on Aggressive Behavior, Aggressive Cognition, Aggressive Affect, Physiological Arousal, and Prosocial Behavior: A Meta-Analytic Review of the Scientific Literature." Psychological science 12, no. 5 (2001): 353-59.

—_. "The Effects of Media Violence on Society." Science 295.5564 (2002): 2377-2379.

Anderson, Craig A. "An Update on the Effects of Playing Violent Video Games."Journal of Adolescence 27.1 (2004): 113-122.

__. "Media Violence and the American Public Revisited." (2002).

Baumann, Robert, Taylor Ciavarra, Bryan Englehardt, and Victor A Matheson. "Sports Franchises, Events, and City Livability: An Examination of Spectator Sports and Crime Rates." The Economic and Labour Relations Review 23, no. 2 : 83-97. (2012).

Braga, Anthony A., Andrew V. Papachristos, and David M. Hureau. "The effects of hot spots policing on crime: An updated systematic review and meta-analysis." Justice Quarterly aheadof-print (2012): 1-31.

Burnett, John. Idle Hands: The Experience of Unemployment, 1790-1990. Routledge (2002).

Card and Dahl (2011) "Family Violence and Football: The Effect of Unexpected Emotional Cues on Violent Behavior" Quarterly Journal of Economics 126(1) 103-143.

Clarke, Ronald. Situational Crime Prevention. Criminal Justice Press. (1997).

Cunningham, A. Scott, Benjamin Engelstätter, and Michael R. Ward. "Understanding the effects of violent video games on violent crime." No. 11-042. ZEW Discussion Papers, (2011).

Dahl, Gordon, and Stefano DellaVigna. "Does movie violence increase violent crime?." The Quarterly Journal of Economics 124.2 (2009): 677-734.

Duwe, Grant. "The benefits of keeping idle hands busy: The impact of a prisoner reentry employment program on post-release employment and offender recidivism." Crime \& Delinquency (2012). 
Griffith, Mark, and Mike Sutton. "Proposing the Crime Substitution Hypothesis: Exploring the

possible causal relationship between excessive adolescent video game playing, social networking and crime reduction." Education and Health Journal, vol 31, number 1 (20130.

Jacob, Brian, Lars Lefgren, and Enrico Moretti. "The Dynamics of Criminal Behaviour: Evidence from Weather Shocks,” Journal of Human Resources, 42, 489-527. (2007)

Kirby, Stuart, Brian Francis, and Rosalie O'Flaherty. "Can the FIFA World Cup Football (Soccer) Tournament be Associated with an Increase in Domestic Abuse?." Journal of Research in Crime and Delinquency . (2013)

Marie, Olivier. "Police and Thieves in the Stadium: Measuring the (Multiple) Effects of Football Matches on Crime." Research centre for education and the Labour Market (ROA), Faculty of Economics and Business Administration, Maastricht University (2010).

Nichols, A. Regression for Nonnegative Skewed Dependent Variables. BOS10 Stata Conference 2, Stata Users Group, July 15-16, in Boston, United States of America. (2010).

Rees, Daniel I, and Kevin T Schnepel. "College Football Games and Crime." Journal of Sports Economics 10, no. 1 (2009): 68-87.

Skogan, Wesley, and Kathleen Frydl, eds. Fairness and effectiveness in policing: the evidence. National Academies Press. (2004).

Uhlmann, Eric, and Jane Swanson. "Exposure to Violent Video Games Increases Automatic Aggressiveness." Journal of adolescence 27, no. 1 (2004): 41-52.

Ward, Michael R. "Video games and crime." Contemporary Economic Policy29.2 (2011): 261273.

Warner, Barbara D., and Brandi Wilson Coomer. "Neighborhood drug arrest rates: are they a meaningful indicator of drug activity? A research note." Journal of Research in Crime and Delinquency 40, no. 2 (2003): 123-138.

Weisburd, David, Laura A. Wyckoff, Justin Ready, John E. Eck, Joshua C. Hinkle, and Frank Gajewski. "Does Crime Just Move Around The Corner? A Controlled Study of Spatial Displacement and Diffusion Of Crime Control Benefits." Criminology 44, no. 3 (2006): 549-592.

Wooldridge, Jeffrey. Introductory Econometrics: A Modern Approach. Cengage Learning. 
(2012).

Zimring, Franklin E, and Gordon Hawkins. Crime Is Not the Problem: Lethal Violence in America. Oxford University Press New York. (1997). 


\section{Appendix}

Supplementary OLS Models:

Table 5. Bulls Playoff Games: Crimes per Half-hour

\begin{tabular}{|c|c|c|c|c|c|}
\hline & Total & Property & Violent & Drugs & Other \\
\hline $3.0 \mathrm{hrs}$ pre & $-0.055(0.784)$ & $0.530(0.483)$ & $-0.530(0.478)$ & $-0.048(0.214)$ & $-0.119(0.208)$ \\
\hline $2.5 \mathrm{hrs}$ pre & $-0.202(0.577)$ & $-0.463(0.358)$ & $-0.515(0.325)$ & $0.284(0.211)$ & $0.412^{* *}(0.159)$ \\
\hline $2.0 \mathrm{hrs}$ pre & $-0.460(0.732)$ & $0.266(0.549)$ & $-0.434(0.417)$ & $-0.307(0.221)$ & $0.035(0.202)$ \\
\hline $1.5 \mathrm{hrs}$ pre & $0.155(0.618)$ & $-0.244(0.342)$ & $0.030(0.372)$ & $0.361(0.225)$ & $-0.192(0.172)$ \\
\hline $1.0 \mathrm{hrs}$ pre & $0.236(0.793)$ & $-0.214(0.466)$ & $0.540(0.365)$ & $-0.038(0.250)$ & $-0.208(0.207)$ \\
\hline $0.5 \mathrm{hrs}$ pre & $-0.285(0.701)$ & $-0.226(0.408)$ & $-0.227(0.365)$ & $0.062(0.244)$ & $-0.056(0.204)$ \\
\hline Game 0-.5 hr & $-0.213(0.732)$ & $-1.053^{*}(0.532)$ & $0.604(0.428)$ & $-0.006(0.273)$ & $0.171(0.218)$ \\
\hline Game .5-1 hr & $-0.917(0.618)$ & $-0.255(0.398)$ & $-0.384(0.324)$ & $-0.324(0.245)$ & $-0.108(0.183)$ \\
\hline Game 1-1.5 hr & $-1.764^{* *}(0.626)$ & $-1.085^{*}(0.428)$ & $-0.120(0.418)$ & $-0.502(0.304)$ & $-0.116(0.220)$ \\
\hline Game 1.5-2 hr & $-1.139(0.709)$ & $-0.304(0.427)$ & $-0.605(0.355)$ & $-0.134(0.276)$ & $-0.009(0.236)$ \\
\hline Game $2-2.5 \mathrm{hr}$ & $-1.326(0.772)$ & $-0.909^{*}(0.421)$ & 0.172 (0.495) & $-0.446(0.316)$ & $-0.205(0.241)$ \\
\hline Game 2.5-3 hr & $-0.451(0.695)$ & $-0.344(0.450)$ & $0.580(0.450)$ & $-0.391(0.255)$ & $-0.420(0.237)$ \\
\hline $0.5 \mathrm{hrs}$ post & $-1.725(0.910)$ & $-0.725(0.509)$ & $-0.659(0.489)$ & $-0.171(0.324)$ & $-0.249(0.233)$ \\
\hline $1.0 \mathrm{hrs}$ post & $-1.034(0.733)$ & $-0.056(0.477)$ & $-0.753^{*}(0.317)$ & $0.065(0.273)$ & $-0.167(0.178)$ \\
\hline $1.5 \mathrm{hrs}$ post & $-0.197(0.904)$ & $-0.425(0.540)$ & $0.200(0.439)$ & $0.036(0.316)$ & $-0.081(0.240)$ \\
\hline $2.0 \mathrm{hrs}$ post & $-0.502(0.606)$ & $-0.577(0.429)$ & $-0.011(0.346)$ & $0.051(0.242)$ & $0.005(0.159)$ \\
\hline $2.5 \mathrm{hrs}$ post & $-1.822(1.131)$ & $-1.424(0.764)$ & $-0.193(0.464)$ & $-0.035(0.244)$ & $-0.319(0.214)$ \\
\hline $3.0 \mathrm{hrs}$ post & $0.848(0.623)$ & $0.431(0.405)$ & $0.188(0.315)$ & $0.266(0.197)$ & $-0.025(0.142)$ \\
\hline
\end{tabular}

Notes: $* * *$ Significant at the 0.1 percent level. **Significant at the 1 percent level. *Significant at the 5 percent level. 
Table 6. MLB Playoffs: Crimes per Half-hour

\begin{tabular}{|c|c|c|c|c|c|}
\hline & Total & Property & Violent & Drugs & Other \\
\hline $3.0 \mathrm{hrs}$ pre & $-2.064(1.417)$ & $-1.493^{*}(0.711)$ & $-0.261(0.682)$ & $-0.074(0.827)$ & $-0.223(0.253)$ \\
\hline $2.5 \mathrm{hrs}$ pre & $-1.871(1.124)$ & $-1.049(0.699)$ & $0.429(0.534)$ & $-0.361(0.739)$ & $-0.669^{* *}(0.210)$ \\
\hline $2.0 \mathrm{hrs}$ pre & $-0.243(1.557)$ & $0.613(0.800)$ & $-0.085(0.760)$ & $0.047(0.893)$ & $-0.283(0.274)$ \\
\hline $1.5 \mathrm{hrs}$ pre & $-1.993(1.019)$ & $-1.679^{* *}(0.643)$ & $0.039(0.564)$ & $-0.074(0.664)$ & $0.088(0.283)$ \\
\hline $1.0 \mathrm{hrs}$ pre & $1.319(1.369)$ & $1.058(0.853)$ & $-0.587(0.698)$ & $0.765(1.068)$ & $0.214(0.372)$ \\
\hline 0.5 hrs pre & $-1.062(1.336)$ & $-1.263(0.791)$ & $-0.037(0.577)$ & $-0.016(0.425)$ & $0.351(0.280)$ \\
\hline Game 0-.5 hr & $-2.210(1.484)$ & $-1.382(1.064)$ & $-0.428(0.684)$ & $-0.840(0.579)$ & $0.258(0.355)$ \\
\hline Game .5-1 hr & $-2.552^{*}(1.281)$ & $-1.460(0.792)$ & $-0.005(0.599)$ & $-0.664(0.765)$ & $-0.365(0.226)$ \\
\hline Game 1-1.5 hr & -1.636 (1.377) & $-0.324(0.911)$ & $-0.632(0.569)$ & $-0.687(0.781)$ & $-0.131(0.347)$ \\
\hline Game 1.5-2 hr & $-2.560(1.357)$ & $-0.619(0.637)$ & $-0.518(0.767)$ & $-1.687^{*}(0.726)$ & $0.131(0.345)$ \\
\hline Game 2-2.5 hr & $-3.483^{* *}(1.234)$ & $-0.487(0.849)$ & $-0.645(0.669)$ & $-1.562^{* *}(0.531)$ & $-0.722^{* *}(0.268)$ \\
\hline Game $2.5-3 \mathrm{hr}$ & $-3.655^{* *}(1.121)$ & $-0.879(0.626)$ & $-0.062(0.705)$ & $-1.847^{* * *}(0.557)$ & $-0.904^{* *}(0.275)$ \\
\hline $0.5 \mathrm{hrs}$ post & $-1.883(1.144)$ & $1.236(0.791)$ & $-0.731(0.775)$ & $-1.776^{* * *}(0.445)$ & $-0.463(0.304)$ \\
\hline $1.0 \mathrm{hrs}$ post & $-0.363(1.119)$ & $-0.129(0.759)$ & $0.991(0.598)$ & $-1.319^{* *}(0.444)$ & $0.023(0.381)$ \\
\hline $1.5 \mathrm{hrs}$ post & $1.568(1.273)$ & $0.410(0.733)$ & $1.019(0.675)$ & $-0.009(0.391)$ & $0.049(0.391)$ \\
\hline $2.0 \mathrm{hrs}$ post & $0.364(0.861)$ & $0.942(0.604)$ & $0.949(0.624)$ & $-0.929^{* *}(0.344)$ & $-0.316(0.349)$ \\
\hline $2.5 \mathrm{hrs}$ post & $-0.234(1.466)$ & $-0.660(0.994)$ & $1.016(0.612)$ & $-0.065(0.390)$ & $-0.505(0.375)$ \\
\hline 3.0 hrs post & $0.680(1.154)$ & $-0.011(0.770)$ & $0.604(0.615)$ & $-0.242(0.334)$ & $0.329(0.369)$ \\
\hline
\end{tabular}

Notes: ***Significant at the 0.1 percent level. **Significant at the 1 percent level. *Significant at the 5 percent level. 
Table 7. NBA Finals Games: Crimes per Half-hour

\begin{tabular}{|c|c|c|c|c|c|}
\hline & Total & Property & Violent & Drugs & Other \\
\hline $3.0 \mathrm{hrs}$ pre & $0.206(0.719)$ & $0.166(0.501)$ & $-0.427(0.407)$ & $-0.138(0.190)$ & $0.456^{*}(0.207)$ \\
\hline $2.5 \mathrm{hrs}$ pre & $-0.245(0.682)$ & $-0.205(0.449)$ & $-0.099(0.426)$ & $0.423^{*}(0.193)$ & $-0.257(0.149)$ \\
\hline $2.0 \mathrm{hrs}$ pre & $-0.027(0.803)$ & $-0.133(0.591)$ & $0.071(0.384)$ & $-0.039(0.238)$ & $0.028(0.232)$ \\
\hline $1.5 \mathrm{hrs}$ pre & $-0.706(0.654)$ & $-0.131(0.482)$ & $-0.330(0.353)$ & $-0.156(0.253)$ & $0.115(0.178)$ \\
\hline $1.0 \mathrm{hrs}$ pre & $-2.116^{*}(0.829)$ & $-0.500(0.548)$ & $-0.545(0.440)$ & $-0.264(0.266)$ & $-0.544^{*}(0.227)$ \\
\hline $0.5 \mathrm{hrs}$ pre & $-0.222(0.720)$ & $-0.049(0.437)$ & $-0.622(0.420)$ & $0.237(0.287)$ & $0.086(0.231)$ \\
\hline Game 0-.5 hr & $0.047(0.737)$ & $0.090(0.545)$ & $-0.350(0.421)$ & $0.217(0.311)$ & $-0.144(0.250)$ \\
\hline Game .5-1 hr & $-0.989(0.694)$ & $-0.561(0.353)$ & $-0.212(0.430)$ & $0.121(0.264)$ & $-0.291(0.220)$ \\
\hline Game 1-1.5 hr & $-1.096(0.906)$ & $0.130(0.517)$ & $-0.621(0.465)$ & $-0.212(0.335)$ & $-0.504^{*}(0.227)$ \\
\hline Game 1.5-2 hr & $-0.650(0.748)$ & $-0.441(0.426)$ & $-0.342(0.429)$ & $0.315(0.288)$ & $-0.249(0.192)$ \\
\hline Game $2-2.5 \mathrm{hr}$ & -1.820 (0.967) & $-0.908(0.562)$ & $-0.628(0.478)$ & $-0.217(0.336)$ & $0.017(0.270)$ \\
\hline Game 2.5-3 hr & $-2.638^{* * *}(0.762)$ & $-1.412^{* *}(0.484)$ & $-0.898^{*}(0.457)$ & $0.089(0.273)$ & $-0.267(0.232)$ \\
\hline $0.5 \mathrm{hrs}$ post & $-2.582^{* *}(0.796)$ & $-1.626^{* *}(0.551)$ & $-0.348(0.489)$ & $-0.153(0.300)$ & $-0.345(0.194)$ \\
\hline $1.0 \mathrm{hrs}$ post & $-0.392(0.643)$ & $-0.376(0.377)$ & $-0.260(0.442)$ & $-0.029(0.229)$ & $0.266(0.198)$ \\
\hline $1.5 \mathrm{hrs}$ post & $-0.687(1.315)$ & $-0.237(0.913)$ & $-0.822(0.486)$ & $0.202(0.247)$ & $0.374(0.252)$ \\
\hline $2.0 \mathrm{hrs}$ post & $-1.097(0.926)$ & $0.056(0.586)$ & $-0.972^{*}(0.436)$ & $0.080(0.197)$ & $-0.097(0.191)$ \\
\hline $2.5 \mathrm{hrs}$ post & $-0.828(0.813)$ & $-0.215(0.541)$ & $-1.017^{*}(0.446)$ & $0.145(0.166)$ & $0.101(0.186)$ \\
\hline $3.0 \mathrm{hrs}$ post & $-0.353(0.572)$ & $-0.396(0.328)$ & $-0.329(0.414)$ & $0.495^{* *}(0.169)$ & $-0.107(0.142)$ \\
\hline
\end{tabular}


Table 8. World Series: Crimes per Half-hour

\begin{tabular}{|c|c|c|c|c|c|}
\hline & Total & Property & Violent & Drugs & Other \\
\hline $3.0 \mathrm{hrs}$ pre & $-0.222(0.675)$ & $0.226(0.393)$ & $0.237(0.364)$ & $-0.557(0.285)$ & $-0.241(0.173)$ \\
\hline $2.5 \mathrm{hrs}$ pre & $-0.862(0.628)$ & $-0.105(0.412)$ & $-0.610(0.395)$ & $-0.388(0.267)$ & $0.051(0.201)$ \\
\hline $2.0 \mathrm{hrs}$ pre & $0.203(0.664)$ & $0.544(0.510)$ & $-0.585(0.389)$ & $0.049(0.326)$ & $0.187(0.206)$ \\
\hline $1.5 \mathrm{hrs}$ pre & $-0.808(0.760)$ & $-0.399(0.489)$ & $-0.345(0.408)$ & $-0.164(0.254)$ & $0.180(0.167)$ \\
\hline $1.0 \mathrm{hrs}$ pre & $-0.305(0.799)$ & $0.060(0.527)$ & $0.083(0.383)$ & $-0.200(0.233)$ & $-0.411^{*}(0.172)$ \\
\hline $0.5 \mathrm{hrs}$ pre & $-0.252(0.871)$ & $0.107(0.596)$ & $-0.125(0.393)$ & $0.235(0.274)$ & $-0.305(0.191)$ \\
\hline Game 0-.5 hr & $-0.517(0.815)$ & $-0.389(0.603)$ & $-0.012(0.417)$ & $0.071(0.269)$ & $-0.059(0.195)$ \\
\hline Game .5-1 hr & $-0.573(0.800)$ & $-0.310(0.541)$ & $-0.302(0.364)$ & $-0.212(0.322)$ & $-0.097(0.246)$ \\
\hline Game 1-1.5 hr & $0.174(0.877)$ & $0.843(0.480)$ & $-0.464(0.411)$ & $-0.064(0.329)$ & $-0.243(0.234)$ \\
\hline Game 1.5-2 hr & $-0.752(0.949)$ & $-0.050(0.561)$ & $-0.456(0.401)$ & $-0.352(0.326)$ & $-0.059(0.235)$ \\
\hline Game 2-2.5 hr & $-1.487(0.902)$ & $-0.675(0.559)$ & $-0.229(0.439)$ & $-0.404(0.369)$ & $-0.188(0.184)$ \\
\hline Game 2.5-3 hr & $-0.533(0.943)$ & $0.423(0.606)$ & $-0.545(0.467)$ & $-0.170(0.396)$ & $-0.303(0.199)$ \\
\hline $0.5 \mathrm{hrs}$ post & $-1.168(0.889)$ & $-0.787(0.490)$ & $-0.355(0.389)$ & $-0.205(0.364)$ & $0.025(0.214)$ \\
\hline $1.0 \mathrm{hrs}$ post & $0.214(0.758)$ & $0.422(0.498)$ & $0.122(0.371)$ & $-0.212(0.274)$ & $-0.098(0.189)$ \\
\hline $1.5 \mathrm{hrs}$ post & $-1.671^{*}(0.754)$ & $0.248(0.483)$ & $-1.063^{* *}(0.353)$ & $-0.689 *(0.279)$ & $-0.051(0.186)$ \\
\hline $2.0 \mathrm{hrs}$ post & $0.140(1.068)$ & $0.944(0.753)$ & $-0.121(0.376)$ & $-0.474^{*}(0.214)$ & $-0.052(0.187)$ \\
\hline $2.5 \mathrm{hrs}$ post & $-1.074(1.041)$ & $-0.408(0.750)$ & $0.226(0.396)$ & $-0.458^{*}(0.203)$ & $-0.303(0.209)$ \\
\hline $3.0 \mathrm{hrs}$ post & $0.332(0.815)$ & $1.117(0.597)$ & $-0.546(0.392)$ & $0.016(0.212)$ & $-0.124(0.198)$ \\
\hline
\end{tabular}


Placebo Test:

Table 9: Placebo Test (Monday Night Schedule on Tuesday: Crimes per Half-hour)

\begin{tabular}{|c|c|c|c|c|c|}
\hline & $\begin{array}{l}\text { All Crime } \\
\text { (1) }\end{array}$ & $\begin{array}{l}\text { Property } \\
\text { (2) }\end{array}$ & $\begin{array}{l}\text { Violent } \\
\text { (3) }\end{array}$ & $\begin{array}{l}\text { Drugs } \\
(4)\end{array}$ & $\begin{array}{l}\text { Other } \\
\text { (5) }\end{array}$ \\
\hline 3.0 hrs pre & $1.215 \quad(1.708)$ & $1.951(1.052)$ & $-0.383(0.831)$ & $-0.099(0.389)$ & $-0.255(0.348)$ \\
\hline $2.5 \mathrm{hrs}$ pre & $-0.485(1.290)$ & $0.749(0.725)$ & $-1.066(0.750)$ & $-0.266(0.309)$ & $0.098 \quad(0.599)$ \\
\hline $2.0 \mathrm{hrs}$ pre & $5.463 * *(2.060)$ & $2.697 *(1.258)$ & $0.042 \quad(0.671)$ & $0.712 \quad(0.509)$ & $2.012 * * *(0.555)$ \\
\hline $1.5 \mathrm{hrs}$ pre & $-0.680(1.772)$ & $-1.544 \quad(1.343)$ & $0.315 \quad(0.503)$ & $0.048 \quad(0.503)$ & $0.501 \quad(0.397)$ \\
\hline $1.0 \mathrm{hrs}$ pre & $1.150 \quad(1.582)$ & $0.697 \quad(0.791)$ & $-0.074 \quad(0.851)$ & $0.409(0.504)$ & $0.118 \quad(0.550)$ \\
\hline $0.5 \mathrm{hrs}$ pre & $-2.575(1.640)$ & $-0.691(0.828)$ & $-0.089(0.723)$ & $-0.511(0.511)$ & $-1.284 * *(0.415)$ \\
\hline Game $0-.5 \mathrm{hr}$ & $0.021(1.690)$ & $-0.151(1.010)$ & $0.571 \quad(0.767)$ & $-1.025(0.639)$ & $0.625(0.523)$ \\
\hline Game . 5-1 hr & $-1.686(1.729)$ & $-0.840 \quad(1.253)$ & $-0.103(0.748)$ & $-0.277(0.883)$ & $-0.465(0.732)$ \\
\hline Game $1-1.5 \mathrm{hr}$ & 1.034 & $0.276(0.735)$ & $1.127(0.843)$ & $-0.032(0.700)$ & $-0.338(0.464)$ \\
\hline Game $1.5-2 \mathrm{hr}$ & $0.416 \quad(2.397)$ & $0.266(1.265)$ & $-0.749(0.633)$ & $0.792 \quad(0.932)$ & $0.107 \quad(0.627)$ \\
\hline Game $2-2.5 \mathrm{hr}$ & $0.235(1.350)$ & $1.109(0.884)$ & $-1.831 * * *(0.447)$ & $0.691(0.840)$ & $0.266(0.509)$ \\
\hline Game 2.5-3 $\mathrm{hr}$ & $0.895(2.197)$ & $-0.928(1.129)$ & $2.391 *(1.147)$ & $-0.463(0.773)$ & $-0.105(0.534)$ \\
\hline $0.5 \mathrm{hrs}$ post & $0.112(1.398)$ & $0.300 \quad(0.906)$ & $0.507 \quad(0.698)$ & $-0.549(0.520)$ & $-0.146 \quad(0.398)$ \\
\hline $1.0 \mathrm{hrs}$ post & $-0.384 \quad(1.012)$ & $-1.050 \quad(0.840)$ & $0.312(0.811)$ & $0.229 \quad(0.493)$ & $0.124 \quad(0.489)$ \\
\hline $1.5 \mathrm{hrs}$ post & $1.122(0.975)$ & $1.352(0.920)$ & $-0.094 \quad(0.572)$ & $0.074 \quad(0.531)$ & $-0.209 \quad(0.417)$ \\
\hline $2.0 \mathrm{hrs}$ post & $-4.670 *(2.054)$ & $-4.165 * *(1.507)$ & $-0.586 \quad(0.666)$ & $0.164 \quad 0.4$ & -0.083 \\
\hline $2.5 \mathrm{hrs} \mathrm{f}$ & $2.380 * *(0.870)$ & $1.384 *(0.574)$ & $0.625 \quad(0.709)$ & $(0.264)$ & $0.029 \quad(0.288)$ \\
\hline $3.0 \mathrm{hrs}$ post & $-0.912(1.274)$ & $-0.838 \quad(0.845)$ & $-0.161 \quad(0.620)$ & $0.037 \quad(0.323)$ & $0.051 \quad(0.289)$ \\
\hline
\end{tabular}

Notes: ***Significant at the 0.1 percent level. **Significant at the 1 percent level.

*Significant at the 5 percent level. 
Models Including Game Day Indicator:

Table 10. Super Bowl Sunday: Crimes per Half-hour (with Game Day Indicator) Super Bowl Sunday: Crimes per Half-hour (with Game Day Indicator)

\begin{tabular}{|c|c|c|c|c|c|}
\hline & $\begin{array}{c}\text { All Crime } \\
\text { (1) }\end{array}$ & $\begin{array}{c}\text { Property } \\
\text { (2) }\end{array}$ & $\begin{array}{c}\text { Violent } \\
\text { (3) }\end{array}$ & $\begin{array}{c}\text { Drugs } \\
(4)\end{array}$ & $\begin{array}{c}\text { Other } \\
\text { (5) }\end{array}$ \\
\hline gameDay & $-2.087 *(1.020)$ & $-0.548 \quad(0.530)$ & $0.148 \quad(0.604)$ & $-0.878 *(0.440)$ & $-0.810 * * *(0.233)$ \\
\hline 3.0 hrs pre & $-1.372(1.387)$ & $-0.153(0.710)$ & $-0.994 \quad(0.829)$ & $-0.499(0.682)$ & $0.275(0.520)$ \\
\hline 2.5 hrs pre & $-0.341 \quad(2.021)$ & $0.126(1.129)$ & $-0.461(0.893)$ & $-0.981(0.653)$ & $0.975 \quad(0.647)$ \\
\hline 2.0 hrs pre & $1.699(1.612)$ & $0.280 \quad(1.037)$ & $0.871 \quad(0.852)$ & $-0.090 \quad(0.745)$ & $0.638 \quad(0.518)$ \\
\hline 1.5 hrs pre & $-1.634 \quad(2.745)$ & $-1.102(1.276)$ & $0.110(1.451)$ & $-0.867 \quad(0.692)$ & $0.224 \quad(0.661)$ \\
\hline 1.0 hrs pre & $0.276(1.322)$ & $0.226(1.171)$ & $-0.332(0.789)$ & $-0.224 \quad(0.584)$ & $0.605 \quad(0.499)$ \\
\hline 0.5 hrs pre & $-3.325 \quad(2.182)$ & $-1.781(1.456)$ & $-1.198(1.123)$ & $-0.242(0.606)$ & $-0.104 \quad(0.629)$ \\
\hline Game $0-.5 \mathrm{hr}$ & $0.048 \quad(1.804)$ & $1.016(1.175)$ & $-1.721 *(0.827)$ & $0.148(0.811)$ & $0.604 \quad(0.656)$ \\
\hline Game .5-1 hr & $-2.264 \quad(2.546)$ & $-2.365(1.296)$ & $-1.349(1.171)$ & $-0.020(0.618)$ & $1.470(0.946)$ \\
\hline Game $1-1.5 \mathrm{hr}$ & $-3.531 *(1.750)$ & $-1.574(0.818)$ & $-1.687(0.925)$ & $-0.779(0.579)$ & $0.509(0.598)$ \\
\hline Game 1.5-2 $\mathrm{hr}$ & $-5.581 * *(1.736)$ & $-1.600(1.124)$ & $-0.747(1.107)$ & $-3.072 * * *(0.671)$ & $-0.162(0.681)$ \\
\hline Game 2-2.5 hr & $-4.728 * *(1.577)$ & $-0.693(0.982)$ & $-0.541(0.922)$ & $-3.032 * * *(0.598)$ & $-0.462(0.637)$ \\
\hline Game $2 \cdot 5-3 \mathrm{hr}$ & $-9.284 * * *(2.171)$ & $-3.917 * *(1.289)$ & $-0.235(1.237)$ & $-3.256 * * *(0.663)$ & $-1.876 * * *(0.463)$ \\
\hline Game $3-3.5 \mathrm{hr}$ & $-4.672 * *(1.809)$ & $1.168(1.554)$ & $-2.372 *(0.975)$ & $-3.290 * * *(0.591)$ & $-0.178(0.418)$ \\
\hline Game $3 \cdot 5-4 \mathrm{hr}$ & $-6.187 * *(2.112)$ & $-2.837 *(1.386)$ & $-0.374(1.287)$ & $-3.345 * * *(0.667)$ & $0.369 \quad(0.624)$ \\
\hline $0.5 \mathrm{hrs}$ post & $0.262(1.910)$ & $0.837 \quad(1.366)$ & $1.152(0.920)$ & $-1.868 * *(0.672)$ & $0.140 \quad(0.526)$ \\
\hline $1.0 \mathrm{hrs}$ post & $-1.101(2.322)$ & $-2.011(1.157)$ & $2.257(1.238)$ & $-1.738 * *(0.670)$ & $0.391(0.749)$ \\
\hline $1.5 \mathrm{hrs}$ post & $2.415(1.960)$ & $1.667 \quad(0.911)$ & $0.206(1.316)$ & $-0.857 \quad(0.702)$ & $1.399 * *(0.482)$ \\
\hline 2.0 hrs post & $1.498 \quad(1.629)$ & $-1.290(0.873)$ & $2.495(1.314)$ & $-0.197 \quad(0.791)$ & $0.490 \quad(0.438)$ \\
\hline
\end{tabular}

Notes: $\quad * * *$ Significant at the 0.1 percent level.

**Significant at the 1 percent level.

*Significant at the 5 percent level.

Table 11. Monday Night Bears Wins: Crimes per Half-hour (with Game Day Indicator)

\begin{tabular}{|c|c|c|c|c|c|}
\hline & $\begin{array}{c}\text { All Crime } \\
\text { (1) }\end{array}$ & $\begin{array}{l}\text { Property } \\
\text { (2) }\end{array}$ & $\begin{array}{c}\text { Violent } \\
\text { (3) }\end{array}$ & $\begin{array}{c}\text { Drugs } \\
(4)\end{array}$ & $\begin{array}{l}\text { Other } \\
\text { (5) }\end{array}$ \\
\hline gameDay & $-0.271(0.771)$ & $-0.356 \quad(0.384)$ & $-0.161 \quad(0.462)$ & $0.369 \quad(0.193)$ & $-0.123(0.170)$ \\
\hline 3.0 hrs pre & $0.024 \quad(1.146)$ & $1.803(1.038)$ & $-1.476(0.969)$ & $-0.675(0.439)$ & $0.372(0.454)$ \\
\hline 2.5 hrs pre & $-1.063(2.639)$ & $1.572(2.287)$ & $-0.671(1.084)$ & $-1.118 *(0.534)$ & $-0.846(0.579)$ \\
\hline 2.0 hrs pre & $-2.608 *(1.128)$ & $-1.681(0.947)$ & $-0.558 \quad(0.766)$ & $-1.110 * *(0.347)$ & $0.740 *(0.332)$ \\
\hline 1.5 hrs pre & $0.224 \quad(2.248)$ & $-0.319(1.701)$ & $0.328 \quad(1.030)$ & $0.471 \quad(0.699)$ & $-0.255(0.555)$ \\
\hline 1.0 hrs pre & $-1.316(1.215)$ & $-0.907 \quad(0.755)$ & $0.037(1.086)$ & $-0.886(0.587)$ & $0.440 \quad(0.629)$ \\
\hline 0.5 hrs pre & $-1.768 \quad(2.965)$ & $-1.231(2.067)$ & $-1.721(0.932)$ & $0.778 \quad(0.955)$ & $0.406 \quad(0.884)$ \\
\hline Game $0-.5 \mathrm{hr}$ & $-0.662(1.552)$ & $0.698(0.703)$ & $-0.245(0.870)$ & $-0.449(0.620)$ & $-0.666(0.481)$ \\
\hline Game .5-1 hr & $-9.707 * * *(2.189)$ & $-4.129 * *(1.602)$ & $-2.154 * *(0.677)$ & $-2.092 *(0.877)$ & $-1.332(0.754)$ \\
\hline Game $1-1.5 \mathrm{hr}$ & $\varepsilon-6.617 * * *(1.746)$ & $-2.604 *(1.160)$ & $0.105(0.764)$ & $-2.936 * * * \quad(0.476)$ & $-1.183 * *(0.407)$ \\
\hline Game $1.5-2 \mathrm{hr}$ & $E-8.396 * * *(1.959)$ & $-2.261(1.284)$ & $-0.815(0.932)$ & $-4.089 * * * \quad(0.489)$ & $-1.232 *(0.587)$ \\
\hline Game 2-2.5 hr & $c-3.397 * *(1.078)$ & $0.190(0.712)$ & $-0.214(0.900)$ & $-2.141 * * * \quad(0.624)$ & $-1.233 * * *(0.275)$ \\
\hline Game $2 \cdot 5-3 \mathrm{hr}$ & $c-9.985 * * *(2.062)$ & $-3.437 *(1.560)$ & $-1.937(1.053)$ & $-3.617 * * *(0.461)$ & $-0.994 * *(0.305)$ \\
\hline $0.5 \mathrm{hrs}$ post & $-3.038 \quad(1.674)$ & $0.447 \quad(0.875)$ & $-0.977(0.812)$ & $-2.116 * * *(0.601)$ & $-0.392(0.384)$ \\
\hline $1.0 \mathrm{hrs}$ post & $-2.102(2.784)$ & $0.687 \quad(1.419)$ & $-0.284 \quad(1.111)$ & $-1.957 * *(0.712)$ & $(0.599)$ \\
\hline $1.5 \mathrm{hrs}$ post & $0.799 \quad(2.190)$ & $0.096(0.741)$ & $0.442(1.091)$ & $-0.137(0.783)$ & $0.398 \quad(0.503)$ \\
\hline $2.0 \mathrm{hrs}$ post & $(3.644)$ & $-2.821(3.453)$ & $0.343(1.289)$ & $-0.552(0.804)$ & $(1.218)$ \\
\hline $2.5 \mathrm{hrs}$ post & $(1.410)$ & $2.244 * *(0.851)$ & $1.147(0.703)$ & $-0.381 \quad(0.607)$ & $(0.316)$ \\
\hline $3.0 \mathrm{hrs}$ post & $-1.370(1.537)$ & $-0.414 \quad(0.854)$ & $-0.311(1.001)$ & $-1.093 * *(0.369)$ & $0.449(0.615)$ \\
\hline
\end{tabular}

Notes: $\quad * * *$ Significant at the 0.1 percent level.

**Significant at the 1 percent level.

*Significant at the 5 percent level. 